\title{
Geoinformatics tool with an emergy accounting approach for evaluating the sustainability of water systems: Case study of the Lerma river, Mexico
}

\author{
Carlos Roberto Fonseca*, Carlos Díaz-Delgado, María Vicenta Esteller, \\ Daury García-Pulido
}

Centro Interamericano de Recursos del Agua, Facultad de Ingeniería, Universidad Autónoma del Estado de Mexico, Facultad de Ingeniería, Cerro de Coatepec, Ciudad Universitaria s/n CP 50110, Toluca, Estado de Mexico, Mexico, Mexico

\section{A R T I C L E I N F O}

\section{Article history}

Received 9 February 2016

Received in revised form 13 October 2016

Accepted 13 November 2016

\section{Keywords:}

Emergy accounting

Integrated water resources management

Water supply processes

GIS

\begin{abstract}
A B S T R A C T
Emergy theory provides a basis for assessing the added value of water resources as a function of their origin and quality. From this perspective, the sustainability of a water system and its supply to end users may be classified according to the products, services, and energy necessary for its operation, which are incorporated from the corresponding socioeconomic system and form an important aspect of its evaluation. In the present study, the development of a geoinformatics tool with an emergy accounting approach and its corresponding methodology are described, focusing on a spatial-temporal analysis of water resources and their allocation to domestic, industrial, and agricultural uses. In addition, different water provision scenarios that involve several levels of infrastructure in the basin of the Upper Course of the Lerma River (UCLR) are evaluated, and existing water deficits are considered in order to assess their economic impact and offer a perspective on regional environmental sustainability. To achieve this, the water supply processes with the greatest relevance for the UCLR basin are evaluated, which include the extraction of groundwater and the treatment of surface and wastewater for subsequent use. The evaluation of the proposed scenarios indicates that the water supply system where treated water is recycled for agricultural, industrial, and urban uses (with restrictions) has the highest value according to the environmental sustainability index. Beyond this, it is possible to establish a series of strategies to transition from the current scenario where the water supply largely comes from an overexploited aquifer, to one where wastewater treatment plants (WWTP) are capable of implementing additional units in their processes to achieve drinking water quality. Finally, the proposed methodology and the geoinformatics tool developed in this study showed their effectiveness as instruments for achieving an integrated management of water resources, which would facilitate a more objective decision making process based on current and projected scenarios.
\end{abstract}

(c) 2016 Elsevier B.V. All rights reserved.

\section{Introduction}

The evaluation of water resources improves knowledge on the quantity of water that is available within a geographic region, also known as the water availability. However, the use of water resources may be limited by both anthropogenic and natural factors. These restrictions may be defined as: a) economic, in regards to the implementation of infrastructure necessary for water exploita-

\footnotetext{
* Corresponding author.

E-mail addresses: crfonsecao@uaemex.mx (C.R. Fonseca), cdiazd@uaemex.mx (C. Díaz-Delgado), mvestellera@uaemex.mx (M.V. Esteller),dgarciap@uaemex.mx (D. García-Pulido)
}

tion; b) chemical, when the water composition is not apt for the intended use; c) temporal, due to the seasonal variability in hydrological processes; or d) political and social, especially considering the largely conventional or unilateral decisions that are made in regards to the allocation of water resources. Within this framework, an evaluation of water sustainability is necessary in order to improve decision making regarding the allocation of water at distinct scales, allowing for consideration of not only the diverse demands for water but also the limitations and values assigned to different components of the system (WWAP, 2006).

Within the field of water management, one of the most evident problems in evaluating sustainability is the estimation of the economic value of water resources. Currently, the cost com- 
ponent associated with the water supply is largely represented by the economic investment in infrastructure built for enabling water to arrive at its destination (Balairón, 2000). However, this cost is unable to capture all the values and benefits associated with water resources (WWAP, 2006). In this sense, Pulselli et al. (2011a) emphasize the difference between estimating the value of natural resources as economic goods and considering the overall value of natural processes and the presence of environmental conditions that would allow for the provision of environmental goods and services.

In response to the present dilemma, since the second half of the 20th century, theories and their corresponding models have been developed based on the nature and physics of natural resources, rather than from a purely economic standpoint. In addition, the intrinsic value of resources has begun to be calculated from the perspective of the supplier or provider, also known as a "donor-side approach" (Pulselli et al., 2011a; Vassallo et al., 2013).

One of these approaches is encompassed by emergy accounting, which may be conceived of as the available energy that is required, directly or indirectly, to create a product or service (Odum, 1996), and this is commonly calculated for the processes involved in the provision of large scale products or services (Lazzaretto, 2009). For example, Brown et al. (2010) propose estimating the emergy value of water resources using the sustainability criteria established by European norms in regards to water management. In addition, from an emergy accounting standpoint Pulselli et al. (2011b) determined the varying environmental costs of fulfilling demands for both ecological conservation and human consumption along the course of a river.

Other authors have developed informatics tools that facilitate emergy accounting for products based on life-cycle inventories (Marvuglia et al., 2013), as well as for water flows based on information available in global databases (Arbault et al., 2014). Additionally, through the use of geoinformatics tools Mellino et al. (2015) and Díaz-Delgado et al. (2014) were able to include both geographical and temporal variability as elements influencing changes in emergy, in addition to other factors, such as soil organic material, plant and animal biomass, infrastructure constructed by humans, and available water resources.

Following this line of research, the current study presents the development of a geoinformatics tool that: a) conducts an emergy accounting for processes involved in the water supply and b) facilitates an evaluation of regional sustainability by considering the geographic allocation of water resources within the limits of a hydrological watershed.

On one hand, the emergy accounting for supply processes focuses mostly on the energy consumption in both the groundwater extraction and the wastewater treatment. While the first one relies on the power to elevate a water flow rate from a certain depth regarding hydraulic head losses, the wastewater treatment depends on the capacity and type of the treatment plant.

On the other hand, three indicators are estimated in order to evaluate the system. The water deficit for a quantitative assessment of the water allocation. The environmental sustainability index for evaluating the relationship of the emergy yield and the environmental load. And an economic impact as a bridge between emergy accounting and a conventional cost assessment.

As an example, the developed geoinformatics tool is applied to the case study of the Upper Course of the Lerma River (UCLR), Mexico, where the associated aquifer is considered to be overexploited (Fonseca et al., 2013b; Esteller and Díaz-Delgado, 2002) and the surface waters reflect a lower quality than required for human consumption and other activities (Díaz-Delgado et al., 2014).

\section{Basic concepts}

In emergy accounting, different forms of energy may be represented by the equivalent solar emergy, or solar emjoules (seJ), by means of transformity, which reflects the qualitative value of energy ( $\mathrm{Lv}$ and $\mathrm{Wu}, 2009$ ). Concretely, transformity represents the quantity of solar energy required per energy unit or product, expressed in seJ/J or other units. For example, mass (seJ/g) can be expressed as unit emergy values (UEV; Brown et al., 2010; Pulselli et al., 2011b).

Fig. 1 shows an energy flow diagram representing the relationships between the natural and socioeconomic aspects of a water system governed by the hydrological phenomena of water run-off and infiltration. In the water system, the storage elements of surface water or groundwater may be supplied by either renewable or non-renewable resources. This classification is defined by a source criterion, where renewable water resources come directly from local precipitation and non-renewable resources from the exploitation of natural reserves (Díaz-Delgado et al., 2014). In this sense, groundwater that depends on direct recharge by precipitation may also be renewable, while non-renewable sources of surface water may be categorized by the base flow of rivers.

The socioeconomic system is supplied with water resources through supply processes. However, for this to occur, services and infrastructure are necessary, wherein it is possible to attribute to these a flow of emergy. In general, the most common supply processes involve the extraction, channeling, storage, treatment, and distribution of water (Rozos and Makropoulos, 2013). However, in the context of integrated water resources management (and for the goals of the present study), the evaluation, comparisons, and decision making involved in selecting a supply source frequently omit other similar or equivalent processes (such as the transport and storage infrastructure involved in the distribution of water), which are as efficient as their design permits, independent of the origin of the water resource. For the purposes of the present study, the analyzed elements of the supply processes are limited to the extraction of groundwater and type of wastewater treatment, which are the main influential factors governing the environmental and economic impacts of most supply systems (Mo et al., 2011).

In general, a water supply system that exploits groundwater requires more electric energy than a system based on wastewater treatment, although treatment plants may indirectly use an equivalent or greater amount of energy due to their infrastructure and the use of chemical compounds (Mo et al., 2011). The type and size of infrastructure, as well as the quantity of chemicals used, are variables that determine the quality of water entering and leaving different parts of the sub-system. While conventional processes for water treatment consist of primary sedimentation, aeration tanks, sedimentation by gravity, or primary and secondary anaerobic digestion and filtration, in order to achieve drinking water quality, several other processes may be involved, such as coagulation, flocculation, sedimentation, filtration, disinfection by chlorine, or addition of chemicals and sludge treatment (Chung et al., 2008).

\section{Materials and methods}

In addition to accounting the emergy of water resources and their supply processes, an integrated management of water resources requires indicators by which the sustainability of a system can be measured. The indicators proposed in this methodology (Fig. 2) are the water deficit, the environmental sustainability index (ESI), (Buenfil, 2001; Lv and Wu, 2009), and the economic impact of supply processes.

In this methodology some geomatics operations are included, or procedures that depend on the geographical location of vari- 


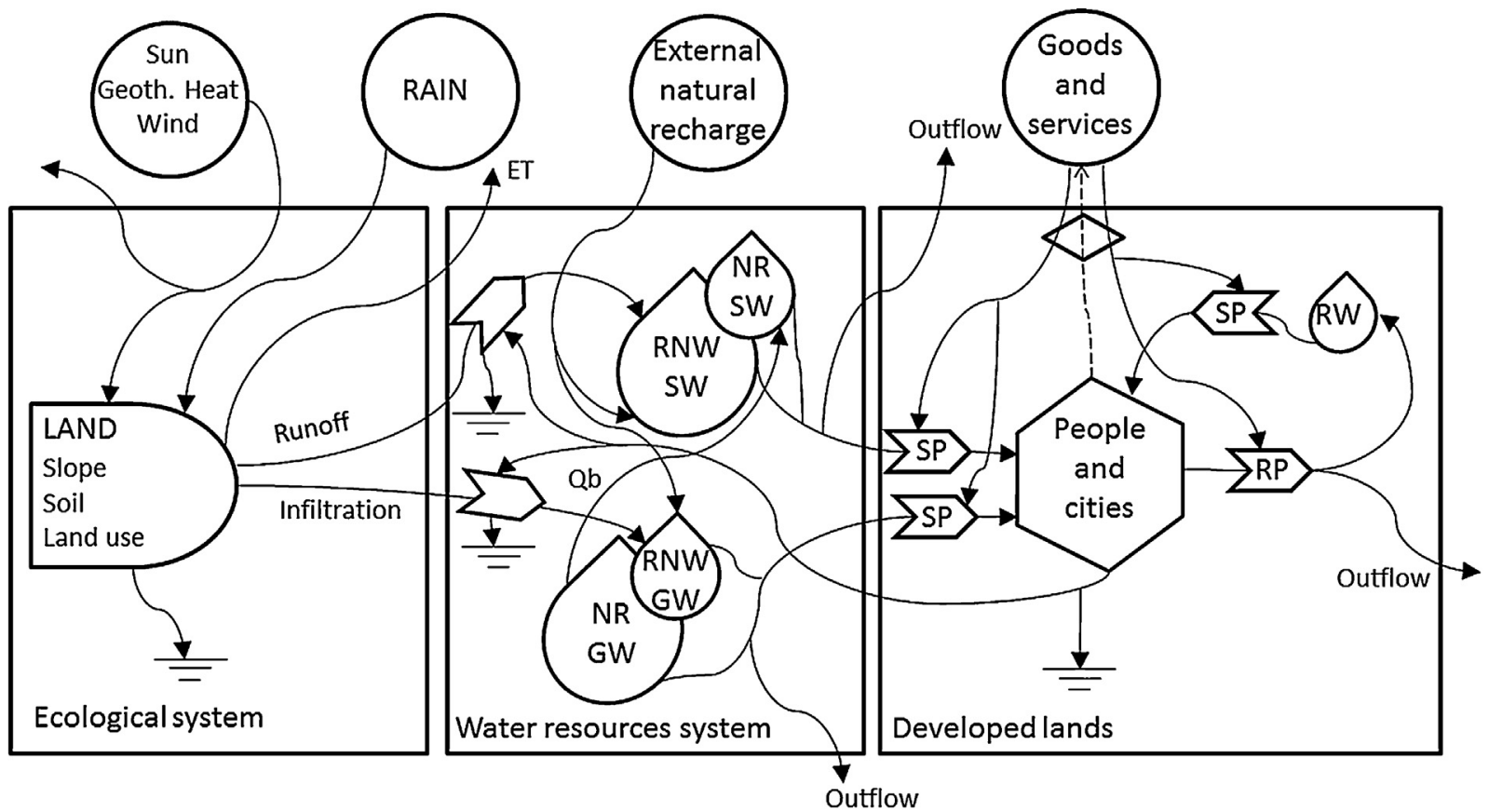

RNW SW: Renewable surface water NR SW: Non-renewable surface water RNW GW: Renewable groundwater
NR GW: Non-renewable groundwater ET: Evapotranspiration $\mathrm{Qb}$ : Base flow
SP: Supply processes

NR GW: Non-renewable groundwater

RP: Recycling processes

Fig. 1. Emergy diagram of the water supply and recycling system (based on Díaz-Delgado et al., 2014).

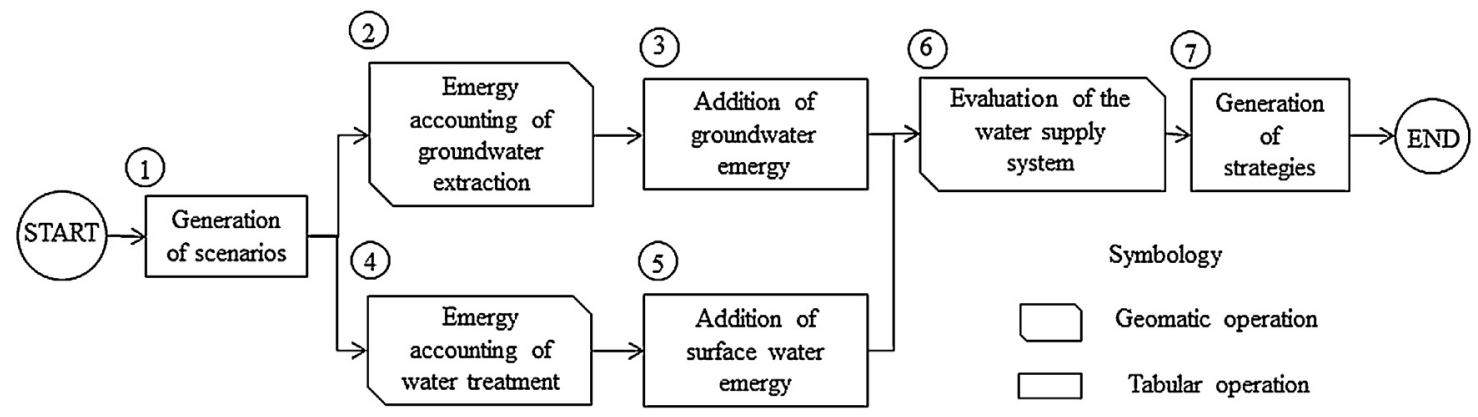

Fig. 2. Methodology of an emergy-based evaluation for the integrated management of water resources.

ables. For these procedures, three modules were designed in the Idrisi informatics platform for Geographic Information Systems (GIS; Eastman, 2006): a) supply process: groundwater extraction, b) supply process: wastewater treatment and c) water supply evaluation.

Before using the modules, the generation of specific scenarios for each case study may be created by examining the socioeconomic system and its initial infrastructure for supplying water from conventional sources (i.e., extraction of surface water and groundwater), in addition to the proposed use of alternative sources (i.e., treated wastewater). However, reliability is also a critical design factor for water supply (Chung et al., 2009) and variability in climatological conditions may result in additional scenarios for the water system if levels of precipitation are also taken into account for low (dry year), medium (average year), or high (wet year) variability.

The first of the geomatics modules (supply process: ground water extraction) is oriented towards estimating the emergy associated with the extraction of groundwater. This flow of emergy is represented as the product of the energy required to elevate water from the groundwater table to the surface and the UEV associated with this effort (for electric energy, this factor acquired an average value of $181,610 \mathrm{seJ} / \mathrm{J}$, in agreement with Odum (1996)). The energy required for pumping water is estimated by the power $\mathrm{P}(\mathrm{J} / \mathrm{s})$ necessary for consumption $\mathrm{Q}\left(\mathrm{m}^{3} / \mathrm{s}\right)$ of water of a density $\rho\left(\mathrm{N} / \mathrm{m}^{3}\right)$ given the hydraulic head $\mathrm{H}(\mathrm{m})$, the gravity acceleration $\mathrm{g}$ and efficiency $\eta$ (Eq. (1)).

$\mathrm{P}=\frac{\mathrm{g} \rho \mathrm{QH}}{\eta}$

The hydraulic head $\mathrm{H}$ depends on the static level of groundwater $\mathrm{Ne}(\mathrm{m})$, as well as losses in water capacity at the aquifer level or in the pumping system (Macdonald et al., 2009). Eq. (2) represents the hydraulic head $\mathrm{H}$ as a function of losses $\mathrm{a}_{1}$ in the aquifer and the hydraulic head $a_{2}$, resulting from losses in the pumping system. In this expression, $\mathrm{T}$ is the transmissivity of the aquifer $\left(\mathrm{m}^{2} / \mathrm{s}\right)$, and $\mathrm{r}$ $(\mathrm{m})$ and $\mathrm{D}(\mathrm{m})$ are the radius and diameter of the well, respectively. $\mathrm{S}$ is the storage coefficient (dimensionless), t the duration of pumping (days), $\alpha$ the Coriolis coefficient (dimensionless), $f$ the pipe friction coefficient (dimensionless, for more information see Eker and Kara (2003)), L (m) the length of the pipe, and $\sum \mathrm{K}$ (dimensionless) the 
Table 1

Emergy of wastewater treatment processes.

\begin{tabular}{|c|c|c|c|c|c|c|}
\hline Process & Installation $^{1}$ & Maintenance $^{1}$ & Human labour ${ }^{1}$ & Consumables $^{2}$ & Electric energy $^{3}$ & Reference \\
\hline Aeration treatment & $6.62 \mathrm{E}+09$ & $2.84 \mathrm{E}+07$ & $6.58 \mathrm{E}+08$ & $3.99 \mathrm{E}+13$ & $3.36 \mathrm{E}+06$ & Vassallo et al. (2009) \\
\hline Activated sludges & $\begin{array}{l}2.91 \mathrm{E}+10 \\
1.65 \mathrm{E}+10\end{array}$ & $\begin{array}{l}0.00 \mathrm{E}+00 \\
0.00 \mathrm{E}+00\end{array}$ & $\begin{array}{l}1.07 \mathrm{E}+10 \\
6.40 \mathrm{E}+09\end{array}$ & $\begin{array}{l}0.00 \mathrm{E}+00 \\
0.00 \mathrm{E}+00\end{array}$ & $\begin{array}{l}1.17 \mathrm{E}+06 \\
1.02 \mathrm{E}+06\end{array}$ & Zhou et al. (2009) \\
\hline Constructed wetlands/Stabilization ponds & $\begin{array}{l}8.35 \mathrm{E}+10 \\
3.04 \mathrm{E}+10\end{array}$ & $\begin{array}{l}0.00 \mathrm{E}+00 \\
0.00 \mathrm{E}+00\end{array}$ & $\begin{array}{l}3.20 \mathrm{E}+09 \\
3.96 \mathrm{E}+09\end{array}$ & $\begin{array}{l}0.00 \mathrm{E}+00 \\
0.00 \mathrm{E}+00\end{array}$ & $\begin{array}{l}2.66 \mathrm{E}+05 \\
4.00 \mathrm{E}+10\end{array}$ & $\begin{array}{l}\text { Zhou et al. (2009) } \\
\text { Arias and Brown (2009) }\end{array}$ \\
\hline Anaerobic reactor & $1.53 \mathrm{E}+10$ & $0.00 \mathrm{E}+00$ & $3.21 \mathrm{E}+09$ & $0.00 \mathrm{E}+00$ & $3.01 \mathrm{E}+06$ & Arias and Brown (2009) \\
\hline Reverse osmosis & $6.08 \mathrm{E}+14$ & $0.00 \mathrm{E}+00$ & $0.00 \mathrm{E}+00$ & $0.00 \mathrm{E}+00$ & $4.16 \mathrm{E}+07$ & Roche et al. (2001) \\
\hline
\end{tabular}

1 Units in seJ per design cubic meter.

2 Units in seJ per operating cubic meter.

3 Units in J per operating cubic meter.

sum of the coefficients of local losses.

$$
\begin{gathered}
\mathrm{H}=\mathrm{N}_{\mathrm{e}}+\mathrm{a}_{1} \mathrm{Q}+\mathrm{a}_{2} \mathrm{Q}^{2}=\mathrm{N}_{\mathrm{e}}+\frac{2.3}{4 \pi \mathrm{T}} \log _{10}\left(\frac{2.25 \mathrm{Tt}}{\mathrm{r}^{2} \mathrm{~S}}\right) \mathrm{Q}+\frac{2}{\mathrm{~g}(\pi D)^{2}} \\
\left(\alpha+\frac{\mathrm{fL}}{\mathrm{D}}+\sum \mathrm{K}\right) \mathrm{Q}^{2}
\end{gathered}
$$

In the case of the wastewater treatment, whose evaluation is carried out by means of the second geomatics module (supply process: wastewater treatment), a fixed emergy value may be approximated given the infrastructure of the system. This is due to the possibility of a homogenous measurement baseline provided by emergy accounting. The evaluation per cubic meter of water, considering the capacity for which wastewater treatment plants (WWTPs) were designed, allows for the consumption of direct and indirect energy by infrastructure of any size to be extrapolated. The results of a literature review are shown in Table 1, demonstrating (in terms of emergy) the consumption of direct and indirect energy from different wastewater treatments. Values of zero indicate values not taken into consideration by the respective authors. In this way, the emergy flow $f_{l}$ associated with the treatment $l$ of a volume $\mathrm{x}_{\mathrm{i}}$ of wastewater is estimated by the use of Eq. (3), where $\mathrm{H}_{\mathrm{Lkl}}$ is the fixed value of emergy based on the installation characteristics and their required maintenance and labor (seJ). Meanwhile, $\mathrm{V}_{\mathrm{k}}$ is the operation volume as determined by the design $\left(\mathrm{m}^{3} / \mathrm{year}\right), \mathrm{Vu}_{\mathrm{k}}$ the useful life (years), $c_{k}$ the UEV associated with acceptable levels of water quality $\left(\mathrm{seJ} / \mathrm{m}^{3}\right)$, E the electric energy $(\mathrm{J})$ required per cubic meter of water, and $\mathrm{T}_{\mathrm{E}}$ the UEV of the electric energy (seJ/J).

$\mathrm{f}_{l}=\sum_{k} \frac{H_{L k l}}{V_{k} V u_{k}}+c_{k} x_{i}+E T_{E} x_{i}$

Afterwards, it is necessary to add to each supply source the added value of the water resources as a function of the required emergy for their processing. In this context, the emergy of water resources is determined by the potential physical and chemical energy of the water (Brown et al., 2010), although in the development of water management strategies, it is only possible to consider the potential chemical energy (Díaz-Delgado et al., 2014). Additionally, the emergy of water resources occurs as a function of the hydrological phenomena and whether water originates from runoff or infiltration (Buenfil, 2001). In this way, the short residence time of surface waters in relationship to groundwater causes the emergy corresponding to surface water to be geographically and temporally variable across a watershed due to the variation in the concentration of dissolved solids at different sections of its rivers throughout the year (Díaz-Delgado et al., 2014).

Once the emergy of water resources and water supply processes under different conditions are obtained, the constructed scenarios may be subjected to an evaluation by means of a third geomatics module (water supply evaluation). The indicators proposed for this evaluation are: the water deficit, the environmental sustainability index, and the economic impact. The first of these represents the difference, if it exists, between the volume of water demand and supply. The environmental sustainability index may be defined as the relationship between emergy yield and the environmental load on the system, taking the form of Eq. (4) (Brown and Ulgiati, 1997; Buenfil, 2001; Almeida et al., 2007; Lv and Wu, 2009), where ESI (dimensionless) is the value for the environmental sustainability index, $\mathrm{R}$ and $\mathrm{N}$ the emergy flow provided by renewable and nonrenewable natural resources (seJ/month), respectively, and $F$ the flow of emergy required from the socioeconomic system in terms of goods and services (seJ/month).

$\mathrm{ESI}=\left(\frac{R+N+F}{F}\right)\left(\frac{R}{N+F}\right)$

In the present study, similar to Díaz-Delgado et al. (2014), renewable water resources are considered to directly originate from precipitation (rates of run-off and infiltration), while nonrenewable resources are a function of the temporal behavior of the groundwater table of an aquifer and are reflected by the recharge index (Van Camp et al., 2010).

Four thresholds have been proposed for reflecting the different states of a system. The first threshold represents a state of null sustainability, or an ESI value equal to 0 . The second threshold encompasses systems with ESI values that reflect an environmental load that is greater than the output $(E S I=1)$. The third threshold indicates a yield ten times greater than the environmental load, resulting in an ESI =10. An example of this state is observed when $60 \%$ of the emergy flow is provided by renewable resources, yet the percentage provided by non-renewable resources $(25 \%)$ is greater than that provided by the economic feedback (15\%). The final threshold is equivalent to a proportion of emergy from renewable resources equal to $80 \%$ and an equilibrium between the emergy from non-renewable resources and economic feedback, an ESI value equal to 40 .

Additionally, the energy required by water supply processes is conditioned by the effect of groundwater table depletion and the necessary treatment required for removing high concentrations of contaminants. Thereby, the economic impact (USD/year) is expressed in equation 5 as the equivalent economic value and defined as the sum of the variable energetic requirements $\mathrm{c}_{\mathrm{e}}\left(\mathrm{J} / \mathrm{m}^{3}\right)$ in relationship to the annual volumetric flow of water $\mathrm{x}\left(\mathrm{m}^{3} / \mathrm{year}\right)$ and the monetary production cost of the electric energy c (USD/J).

$I_{e}=\sum c_{e} x c$

Finally, given the evaluation of the sustainability of the system, it is possible to propose specific strategies that are focused on increasing the use of renewable water resources and reducing the emergy flow generated by supply processes. 


\section{Informatics implementation}

The geomatics modules developed for the present study were constructed in the Delphi language (Borland Software Corporation, 2002) for the Idrisi software package. These modules operate with three basic types of data: a) raster, b) vectorial, and c) tabular. The first of these has a matrix structure (with extension *.rst) and is used to represent georeferenced maps with pixels of different reference values. The second type (with extension *.vct) represents three types of geometric, georeferenced figures (point, line, polygon). The third type is a database (with extension *.mdb) conformed by fields (columns) with data records (rows). In Table 2, the information required for entry, as well as the output data provided by the module, are listed.

The watershed and aquifer may have different delimiting boundaries, for which they are required as inputs in the geomatics module.

Furthermore, the evaluation of the scenarios stems from the concept of a network consisting of a set of nodes and arcs. Although analyzing the volumes of allocated water resources is beyond the scope of this study, it is necessary to understand this aspect of the structure and functioning of the developed geomatics modules. A network is composed of a group of ordered pairs, where each one represents a link (or arc) between a demand node (or user) and a supply node (or supply source). The arcs may be described in terms of the volume of water that is transferred from supply nodes to demand nodes. A variable cost is assigned to this volumetric flow, which may or may not be contained within the maximum or minimum transfer limits. In the current study, the cost must be interpreted as the sum of the emergy flows associated with the transferred water resources, which includes the supply processes necessary for its transference. Therefore, the receptor and supply nodes are characterized, respectively, by the quantity demanded and the maximum capacity for supplying water resources.

The hydrogeological conditions considered in the emergy accounting of the groundwater extraction are the depth of the groundwater table and its maximum level according to historical records, in addition to the depth of the aquifer strata and the values estimated for its storage coefficient and transmissivity. In this same supply process, it is necessary to understand the operating conditions of each extraction well, including the casing diameter of tubing, the friction and local loss coefficients, the efficiency of the pumping equipment, pumping time per year, and cost (in monetary terms) of installation, maintenance, and labor. In the case of wastewater treatment, the characteristics that the database should contain include type of water treatment and water volume according to design and operating capacity.

The emergy accounting for wastewater treatment is based on the values given in Table 1 . However, the seJ $/ \$$ ratio associated with the zone of study, in addition to the transformity values corresponding to water resources and the production of electric energy, are equally required.

In this way, the geomatics modules provide (as coefficients) the energy of the operating systems as well as the emergy associated with the supply processes as a function of the volume assigned to each arc, the classification of transferred water resources as renewable or non-renewable, and finally, water deficits and environmental sustainability indicators (ESI).

\subsection{Module for the emergy accounting of groundwater extraction}

The developed geomatics module for this procedure, and whose flow diagram and interface are shown in Fig. 3 can: a) provide, per arc, the coefficients that determine the emergy associated with the extraction of groundwater, b) determine the capacity of nodes in
Table 2

Inputs and outputs of the geomatics modules.

\begin{tabular}{|c|c|}
\hline Name & Format \\
\hline \multicolumn{2}{|l|}{ Inputs } \\
\hline Watershed/aquifer boundary & Raster ( $\left.{ }^{*} . r s t\right)$ \\
\hline Supply and demand nodes & Vectorial point ( $\left.{ }^{*} . v c t\right)$ \\
\hline Arc and node network & Database (*.mdb) \\
\hline Hydrogeological features & Raster ( $\left.{ }^{*} . r s t\right)$ \\
\hline $\begin{array}{l}\text { Operational characteristics of } \\
\text { groundwater extraction }\end{array}$ & Database $\left({ }^{*} \cdot \mathrm{mdb}\right)$ \\
\hline $\begin{array}{l}\text { Operational characteristics of water } \\
\text { treatment }\end{array}$ & Database $\left({ }^{*} \cdot \mathrm{mdb}\right)$ \\
\hline Emergy of water resources & Raster ( $\left.{ }^{*} . r s t\right)$ \\
\hline \multicolumn{2}{|l|}{ Outputs } \\
\hline $\begin{array}{l}\text { Energy of groundwater extraction and } \\
\text { water treatment }\end{array}$ & Database $\left({ }^{*} . \mathrm{mdb}\right) /$ vectorial or raster \\
\hline Emergy coefficients per arc & Database $\left({ }^{*} \cdot \mathrm{mdb}\right)$ \\
\hline Classification of emergy flow per arc & Database $\left({ }^{*} . \mathrm{mdb}\right)$ \\
\hline Evaluation indicators & Database $\left({ }^{*} . \mathrm{mdb}\right)$ \\
\hline
\end{tabular}

each arc (by constructing a divergence vector), and c) generate the required databases for the system evaluation module.

In relationship to the emergy $f_{l}$ associated with the extraction of groundwater, the module provides four coefficients, $c_{i} \forall i=1,2,3,4$ (generated as four columns in the node network database- Fig. 3a), describing the water flow $x_{l}$ supplied by an arc. The first is an independent term that represents the fixed emergy requirements per installation type and maintenance and labor requirements (estimated in a similar manner in equation 3 for the wastewater treatment infrastructure- Fig. 3b). The other three coefficients are derived from the energy required for pumping groundwater given a variable hydraulic head. More specifically, a re-framed emergy equation (Eq. (2)) is shown for equation 5. In this expression, the second coefficient $c_{2}$ (Fig. $3 c$ ) is a first level degree, composed of the groundwater emergy $\mathrm{T}_{\mathrm{aqf}}\left(\mathrm{sej} / \mathrm{m}^{3}\right)$ and the hydraulic head considering the static level $\mathrm{N}_{\mathrm{e}}$. The third $\mathrm{c}_{3}$ and fourth $\mathrm{c}_{4}$ coefficients (Fig. 3d) are squared and cubic in nature, respectively, and represent the hydraulic head considering friction losses and well efficiency, as was seen in Eq. (2). The denominator $\mathrm{a}_{0}=2.592 \times 10^{6}$ is the conversion factor for considering a monthly flow of water $\left(\mathrm{m}^{3} / \mathrm{month}\right)$ instead of the instantaneous flow in $\mathrm{m}^{3} / \mathrm{s}$.

$$
\begin{aligned}
F_{l}^{\prime} & =c_{1}+c_{2} x_{l}+c_{3} x_{l}^{2}+c_{4} x_{l}^{3}=c_{1}+\left(T_{a q f}+\frac{T_{E} g \rho}{\eta} N_{e}\right) x_{l} \\
& +\left(\frac{T_{E} g \rho}{\eta} \frac{a_{1}}{a_{0}}\right) x_{l}^{2}+\left(\frac{T_{E} g \rho}{\eta} \frac{a_{2}}{a_{0}^{2}}\right) x_{l}^{3}
\end{aligned}
$$

In addition to the coefficients for estimating the emergy associated with the water supply of the arcs, whose nodes of origin are the wells, this module provides the energy (in J/month) consumed per groundwater extraction per well, based on the rate flow of a reference pump. Therefore, it is possible to obtain the energy consumed per well, or rather, an isocontour map of energetic consumption according to pump volumes, similar to that of Fonseca et al. (2013a,b). In this sense, while the energy is estimated individually for each well, a database with information on the operative characteristics is necessary, since in the creation of an isocontour map the operative characteristics concerning water extraction should be equal in order for their interpolation to be solely a function of the depth of the groundwater table.

In the table generated for the construction of the node network, the module provides data columns corresponding to the emergy coefficients for groundwater extraction. However, in the database accessible to the user, another table is also added with the coefficients $c_{2}^{\prime}, c_{3}^{\prime}$, and $c_{4}^{\prime}$, which exclusively represent the energy consumption required to pump up water from the groundwater table to the surface level. 


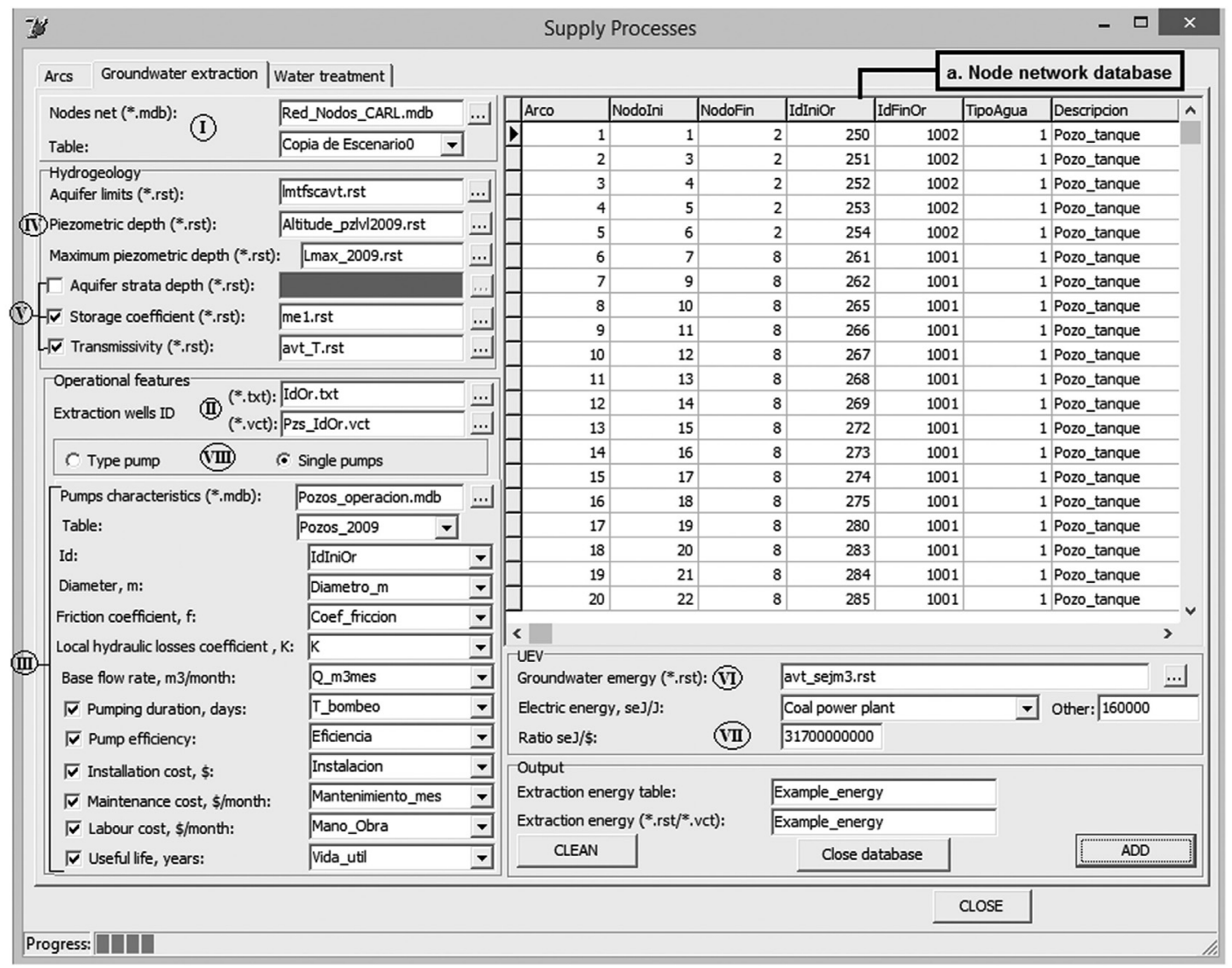

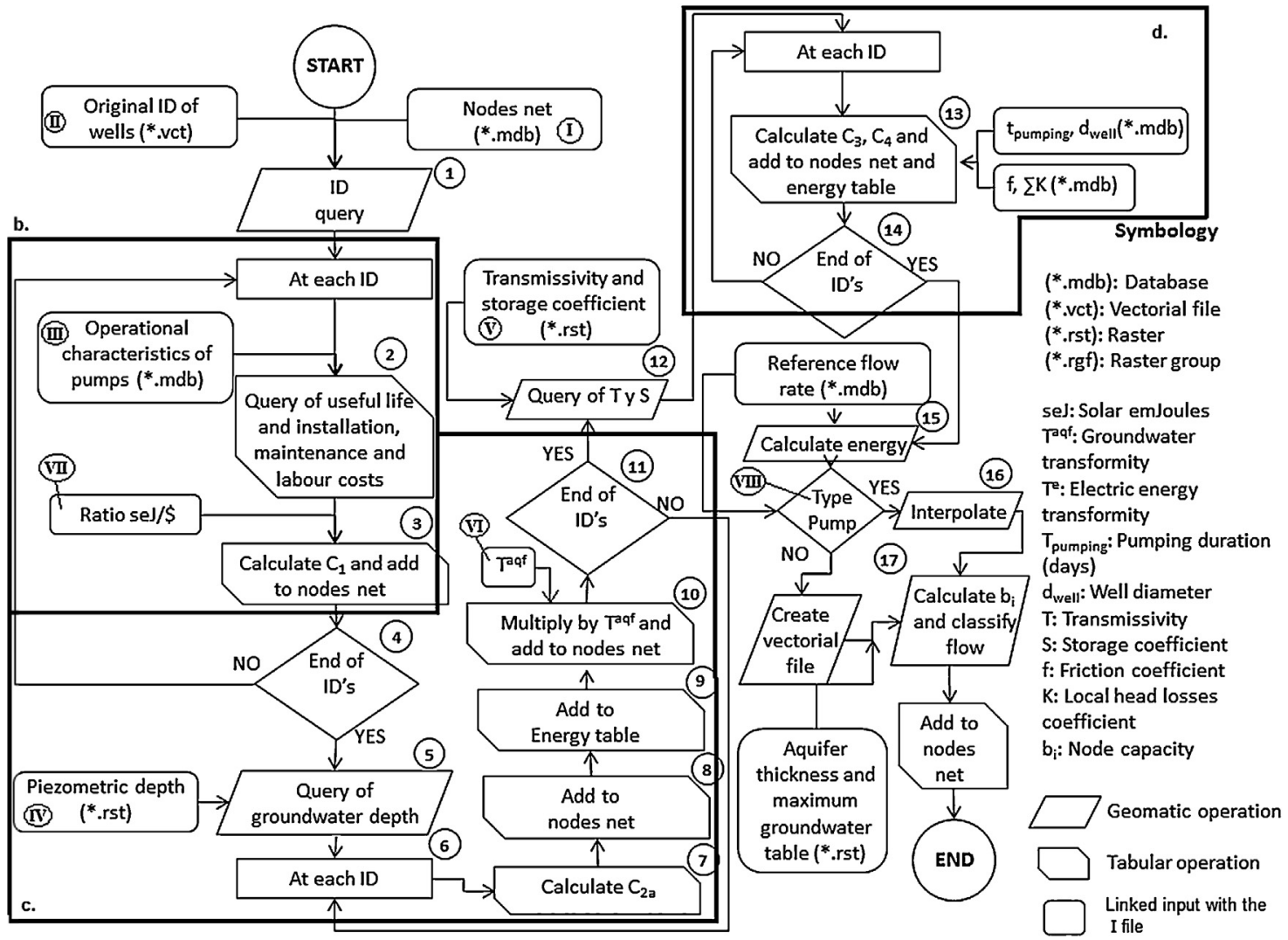

Fig. 3. Flow chart and interface of the module "Supply processes: groundwater extraction". 


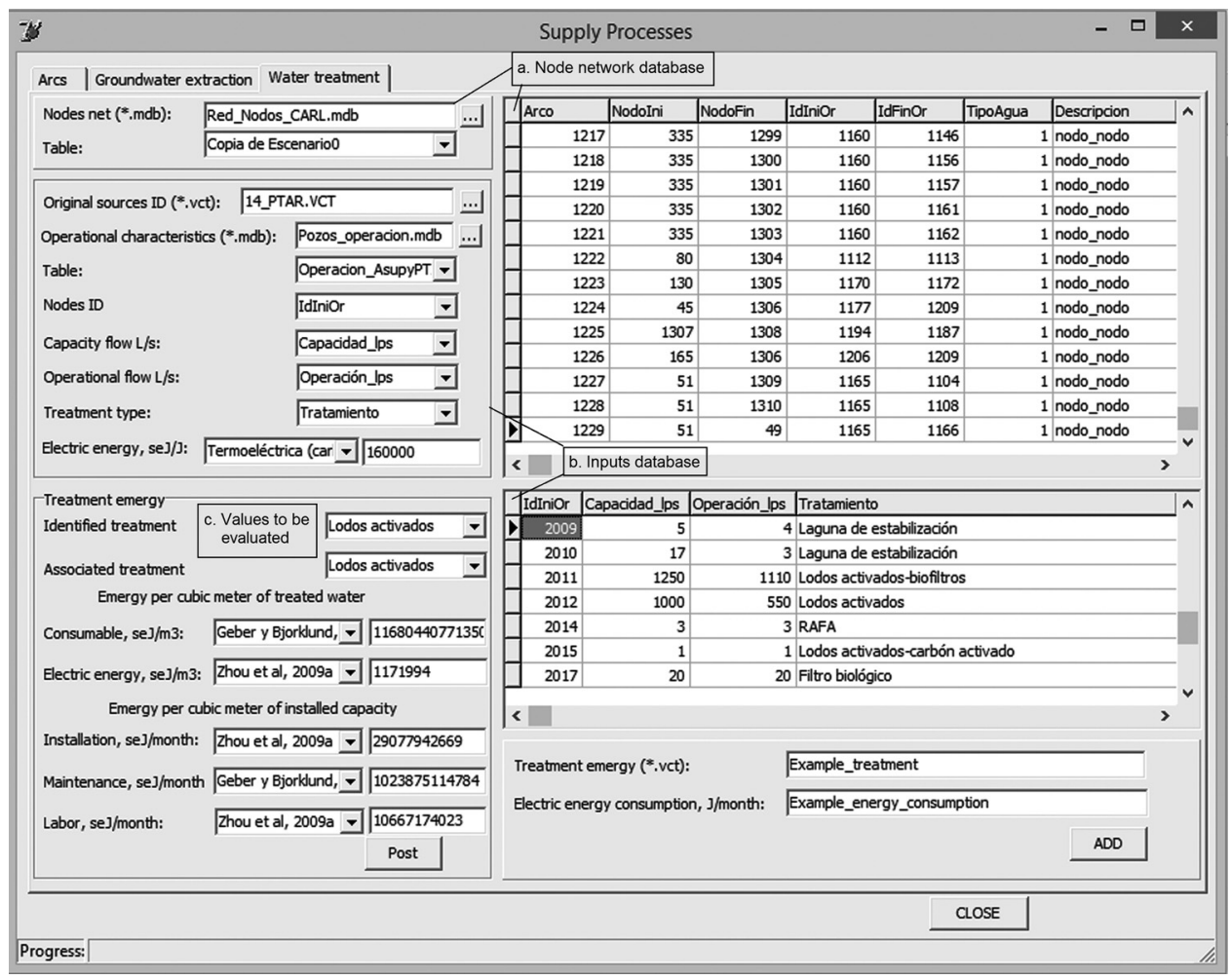

Fig. 4. Interface of the module "Supply processes: water treatment".

With regards to the classification of water resources, from the raster images corresponding to the maximum depth of the groundwater table and the storage coefficient $m$, the module estimates the capacity of node $b_{i}$ (volume per surface area unit) and its renewability classification (Boolean data type, yes/no) in order to be concatenated in the database. If the depth of the current groundwater level $P L_{i}$ at location $i$ is lower than the maximum depth $P L_{\text {maxi }}$, there is a volume $b_{i}$ of water considered to be renewable. To the contrary, the volume is considered to be non-renewable, and it is finite if the depth of the aquifer strata $S L_{i}$ is known (Eq. (6)).

$b_{i}=\left\{\begin{array}{c}\left(P L_{\max i}-P L_{i}\right) m_{i}, \quad s i P L_{i}<P L_{\max i} \\ \left(S L_{i}-P L_{i}\right) m_{i}, \quad s i P L_{i}>P L_{\max i}\end{array}\right.$

\subsection{Module for the emergy accounting in wastewater treatment}

For the analysis corresponding to wastewater treatment, the type of treatment should be identified in the entry database in order for it to be associated with the emergy values found in the literature (Table 1). For this, the capacity of the infrastructure and the operation costs must be specified in the same database. In this case, the independent emergy term is a function of the installation capacity, and the non-lineal coefficients are a function of the operating cost. The module itself performs a series of tabular operations, with the exception of the extraction of the identifiers of wastewater treatment plants from their location vectorial files.

In Fig. 4, where the interface of the module is shown, two spaces are observed that demonstrate the databases. The upper portion corresponds to the node network (Fig. 4a), where the coefficients are aggregated in order to estimate the emergy as a function of the treatment volume. The lower portion shows the table of data inputs (Fig. 4b) that must be entered by the user, in addition to the emergy associated with both the consumables (mainly chemicals) and the electric energy consumed per treated cubic meter of water, along with the installation, maintenance, and labor costs per cubic meter of capacity (Fig. 4c).

\subsection{Module for the evaluation of indicators}

Fundamentally, this module works with the same tabular data obtained from the previous modules for estimating the water deficit, the emergy of supplied water, the environmental sustainability index, and the energy consumed during system operation under several different scenarios. The module provides two functions: evaluation and optimization. By means of the second function, it is possible to obtain the water allocation with the minimum flow of emergy from an offer node to a demand node through a mathematical model, defined as the "minimal cost network flow with bounds on arc flows" (Fonseca, 2014). However, the development of this function is outside the reach of the current work.

During evaluation (Fig. 5), a volumetric flow $\mathrm{x}_{\mathrm{k}}$ of water is associated with each demand node, supposing that water allocation is available via each arc k (Fig. 5a). First, the water deficit is estimated for each demand node, where a deficit is indicated if the sum of the demand and the output directed towards a node is negative, following the same sign conventions used during programming (Fig. 5b). After the operation emergy (Fig. 5c) and the energy (Fig. 5d) value associated with the infrastructure are estimated for each arc, the renewability of water resources is defined by a linear term, based on the data inputs. Once the water resources are classified according to emergy as renewable resources $R_{i j}$ or non-renewable $N_{i j}$ at each node $\mathrm{i}$ and month $\mathrm{j}$, the environmental sustainability index $\mathrm{ESI}_{\mathrm{ij}}$ is estimated in terms of the total emergy $\mathrm{Em}_{\mathrm{ij}}$ (equation 6).

$E S I_{i j}=\left(\frac{E m_{i j}}{E m_{i j}-R_{i j}-N_{i j}}\right)\left(\frac{R_{i j}}{E m_{i j}-R_{i j}}\right)$ 


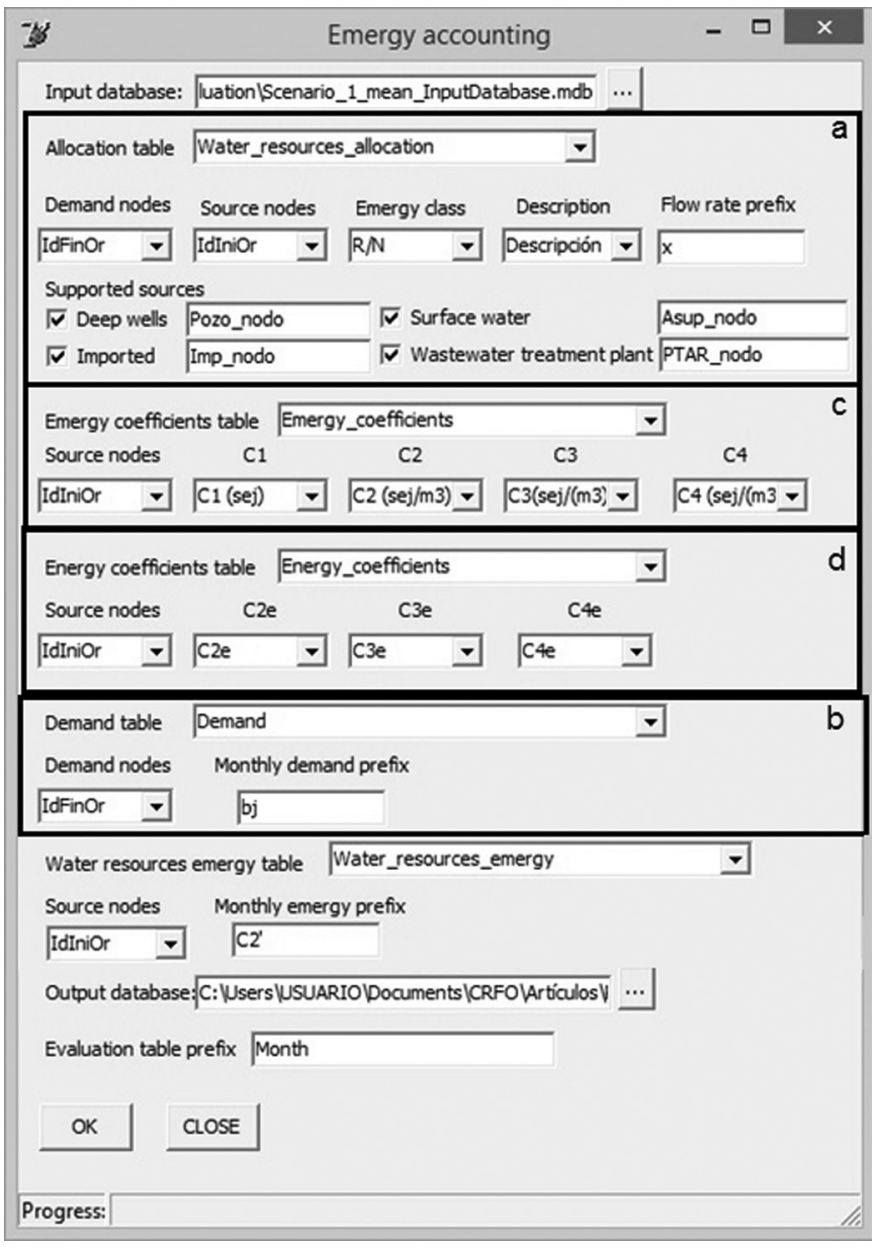

Fig. 5. Interface of the module "Evaluation".

\section{Study area}

The Upper Course of the Lerma River (UCLR) belongs to the Lerma-Santiago-Pacífico basin and forms the region for the case study of the designed modules. With an average altitude of 2600 masl and average annual rainfall of $1200 \mathrm{~mm}$, this watershed has a temperate, sub-humid climate, an average rainfall of $900 \mathrm{~mm}$ in the valley and semi-cold and cold climates in the mountains (Esteller and Díaz-Delgado, 2002). The aquifer of the Toluca Valley (ATV) is unconfined (Esteller et al., 2011) and conformed in large part by granular material with an average hydraulic conductivity of $2 \times 10^{-5} \mathrm{~m} /$ day (Paredes, 2010). According to official data (DOF, 2009), the ATV has a water recharge rate of $336.8 \mathrm{hm}^{3} /$ year, a discharge rate of $53.6 \mathrm{hm}^{3} /$ year, and an extracted volume of $422.4 \mathrm{hm}^{3} /$ year, yet taking into consideration water usage, there is an overall deficit of $152.4 \mathrm{hm}^{3} /$ year that is obtained from groundwater reserves. The overexploitation of ATV is reflected in the continual decrease of the groundwater level from 0.1 to $1.6 \mathrm{~m} / \mathrm{year}$ (Fonseca et al., 2013b), corresponding with the proportion of internal water usage that comes from groundwater resources, at $95.8 \%$, while the remaining portion is imported from neighboring surface waters (Fonseca et al., 2013b; IMTA, 2009). This is due to the fact that the surface waters of the UCLR are not apt for human consumption, which is a product of severe pollution resulting from effluents of industrial and domestic origin.

With regards to internal water consumption, demand for urban use has been estimated for 90 demand nodes to be $111.2 \mathrm{hm}^{3}$ annually, according to the methodology of Fonseca et al. (2013a). The demand for water in the industrial and agricultural sectors was estimated from the number of employees that work in the industrial sector and the surface area of cultivated corn (identified by means of satellite images), respectively. Therefore, the industrial demand for water, distributed in 7 demand nodes, is $14.7 \mathrm{hm}^{3}$ annually, while the agricultural demand, distributed in 20 demand nodes, can reach values of $41.9,74.3$, and $154.7 \mathrm{hm}^{3}$ for a wet, average, or dry year, respectively (Fonseca, 2014).

Of the extracted groundwater, Díaz-Delgado et al. (2014) identified that only $97.31 \mathrm{hm}^{3}$ may be considered to be renewable in the context of integrated water resource management, with an associated emergy value of $1.39 \times 10^{12} \mathrm{seJ} / \mathrm{m}^{3}$. Furthermore, the emergy corresponding to the surface waters of the 11 sub-watersheds has a significant spatial and temporal variation at an average of $2.79 \times 10^{12} \mathrm{seJ} / \mathrm{m}^{3}$ with a standard deviation of $7.17 \times 10^{12} \mathrm{seJ} / \mathrm{m}^{3}$, where the greatest difference in emergy within the same subwatershed was presented for the month of June.

\subsection{Water supply scenarios}

In the context of the current work, four water supply scenarios were considered within the UCLR. The first of these establishes the basis for the current supply conditions "CSC" (considering 2010 as the base year), where urban uses are supplied with water of the highest quality, and water output from wastewater treatment plants is not able to be used. The second scenario, treated wastewater is utilized by the agricultural and industrial sectors "TWAI". The next scenario, treated wastewater is used in agricultural and industrial sectors but also in urban nodes with restrictions "TWAIU", destined for toilets and garden irrigation. Last scenario assumes that wastewater treatment plants have sufficient capacity to ensure that water is drinkable (by the incorporation of reverse osmosis), thereby eliminating restrictions on urban use "DW".

Fig. 6 shows the location of the supply sources considered in the above mentioned scenarios. The groundwater sources are represented by a total of 507 deep wells registered within the limits of the UCLR watershed (not considering the 260 wells whose extracted volume is exported). The casing diameters of the tubing for water transport range from 0.15 to $0.51 \mathrm{~m}$, with a mode of $0.30 \mathrm{~m}$ (IMTA, 2009). The power of the installed pumps reaches $150 \mathrm{HP}$, where upon considering the hydrogeological characteristics, has an inferred extraction capacity from $1.5 \times 10^{3}$ to $2.6 \times 10^{5} \mathrm{~m}^{3} /$ month, with an average of $5 \times 10^{4} \mathrm{~m}^{3} /$ month. The friction coefficient $f$ was calculated from the Nikuradse equation (Sotelo, 2002), where predominantly iron material with a roughness of $0.01 \mathrm{~mm}$ was considered, resulting in values ranging from 0.014 to 0.018 with a mode of 0.015 . For all pumping equipment, a local loss coefficient of $\mathrm{K}=3.74$ was considered, based on the basic components of an extraction station with a useful life of 30 years and the values proposed by Sotelo (2002). The installation cost was estimated from the drilled depth of the well, according to previous investments catalogued by SEMARNAT (2011) and based on the following: 1207 USD/m for wells up to $100 \mathrm{~m}, 1810 \mathrm{USD} / \mathrm{m}$ for up to $200 \mathrm{~m}$, and 2144 $\mathrm{USD} / \mathrm{m}$ for more than $200 \mathrm{~m}$ (average exchange rate for 2011 was MX\$12.43/USD, according to data from the Bank of Mexico, 2015). The average drilling depth for the wells of the Toluca Valley aquifer is $182 \mathrm{~m}$ with a standard deviation of $71 \mathrm{~m}$, a minimum of $43 \mathrm{~m}$, and a maximum of $600 \mathrm{~m}$. The cost of maintenance and the efficiency of the pumping equipment were estimated to be a function of the extracted reference water flow rate, from the data provided by Palacios et al. (2002) and the Secretary of Energy (1997), respectively. The relationship between emergy and economic production, or ratio seJ $/ \$$, was considered equal to $3.17 \times 10^{10} \mathrm{seJ} / \mathrm{MX} \$$, since Brown and Bardi (2001) produced a nationwide estimate of $4 \times 10^{11} \mathrm{seJ} / \mathrm{USD}$. 


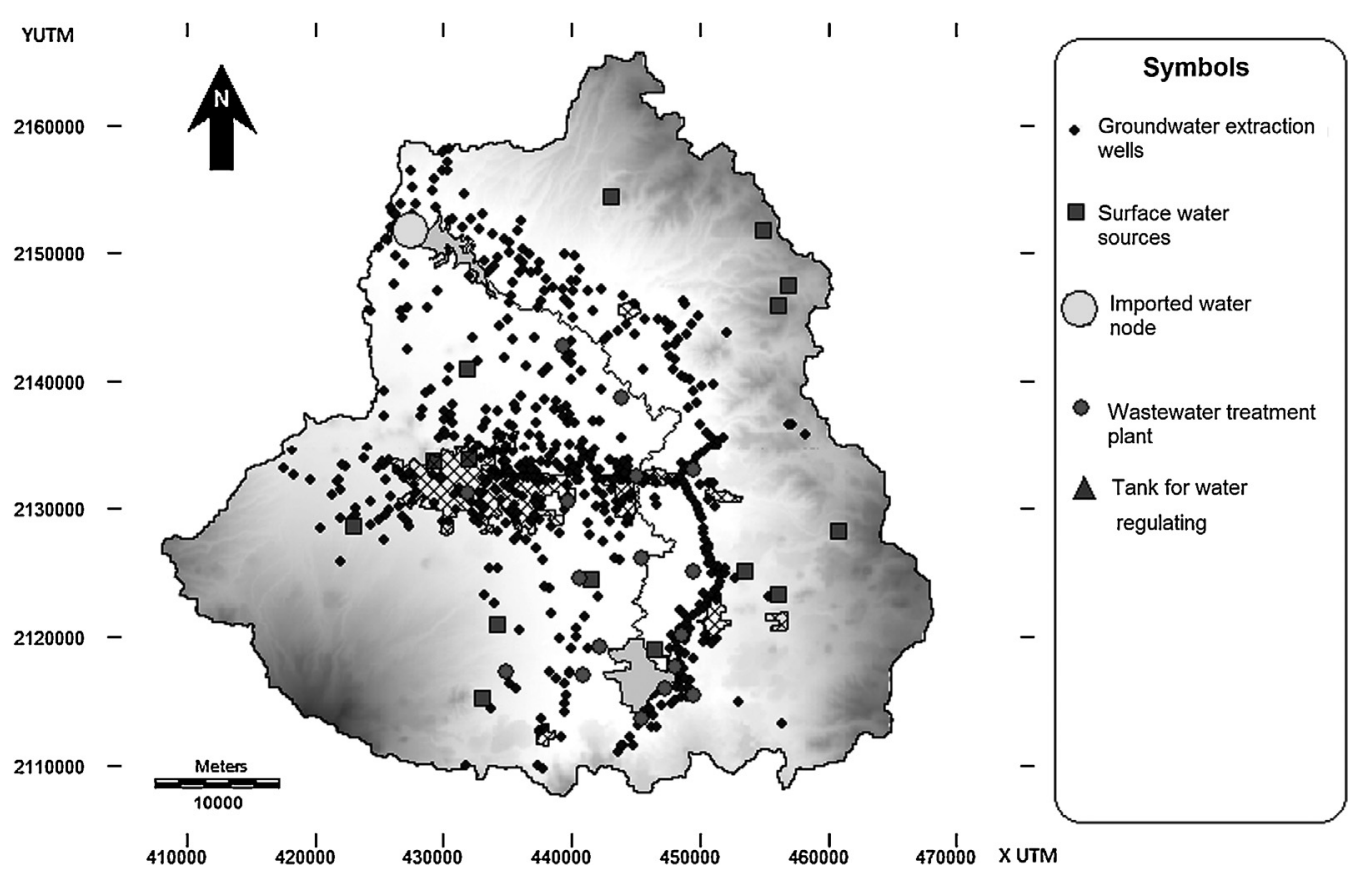

Fig. 6. Water supply sources in the UCLR basin.

The volume of surface water allocated for urban use is approximately $15.6 \mathrm{hm}^{3}$, while agricultural use has an allocated volume of $46.6 \mathrm{hm}^{3}$ (SEMARNAT, 2010a). For wastewater treatment, 17 plants exist in the UCLR, of which five are out of service according to SEMARNAT (2010b). From this same data source, the operational characteristics and treatment type were obtained. Of a total of eight wastewater treatment plants, the majority are stabilization lagoons (5), followed by activated sludge treatment plants (4), aerobic reactors (3), and anaerobic reactors (2). The total capacity of wastewater treatment is $3000 \mathrm{~L} / \mathrm{s}$, although only $2170 \mathrm{~L} / \mathrm{s}$ are treated. For the purposes of the present work, the efficiency of the operating wastewater treatment plants was considered to be satisfactory and to fulfill the corresponding environmental regulations.

\section{Results and discussion}

The emergy accounting associated with the energy required for water supply processes under different scenarios was determined by a group of coefficients forming part of functions, which are also dependent on the monthly volume of water transferred across each arc. In Table 3 , it is possible to observe that the $C_{1}$ coefficients, related to the infrastructure required for supply processes, are greater for the wastewater treatment plants. However, for the functions representing deep wells, the coefficients of the non-linear terms $\left(C_{3}\right.$ and $\left.C_{4}\right)$ are linked with head losses, resulting in a convergence of the unit emergy values (UEV) at a value of approximately $5 \times 10^{4} \mathrm{~m}^{3} /$ month (Fig. 7). Similarly, the UEV associated with the import of water is greater than that of water extracted from wells or produced in wastewater treatment plants, by 50 and $600 \mathrm{~m}^{3} /$ month, respectively, in the most favorable scenario.

The combination of the four types of supply infrastructure proposed by the demand conditions, under dry, average, and wet precipitation regimes, generated 12 possible scenarios, which were evaluated on a monthly basis. Each one of these contemplates up to 91 groups or sources and users (nodes), connected to each other (Fig. 8).

The allocation of water transport volumes from the water supply nodes towards the demand nodes, except in scenario CSC, was based on a network flow of minimal cost with bounds on arc flows (Fonseca, 2014), where the cost is represented by the emergy associated with the water resources as well as with the supply processes.

Table 4 demonstrates the annual volume of water allocated to the different scenarios from the distinct supply sources. The decrease in imported water volume is partially compensated with an increase in the extraction of groundwater. However, the decrease in the annual deficit is mainly provided by recycled wastewater. Following these scenarios, the minimum deficit (16\%) is associated with a wet year under scenario DW. It is worth to highlight that water competition among users is reflected on the temporal trend of water allocation, mainly due to the restriction of links between supply and demand nodes (Fig. 9). For instance, scenario CSC presented a greater average percentage of nodes without water supply ( $23 \%$ of nodes- Fig. 9a), while scenario DW reached the average maximum of completely satisfied nodes ( $64 \%$ of nodesFig. 9b) during a mean year. The decrease of completely satisfied nodes in scenario DW during a wet year is explained by the increase of nodes with deficit up to $50 \%$ (due to more open links between source and demand nodes- figure c). Although in scenarios TWAIU and DW the number of nodes with a high percentage of deficit (>75\%) decreases (Fig. 9d), scenario TWAIU results in an increase of nodes with a deficit just of between 1 and 25\% (Fig. 9e). Overall, the nodes improved their status in comparison to scenario TWAI, shifting from a large deficit of between 51 and $75 \%$ to being completely satisfied.

With regards to emergy accounting, existing literature has synthesized information in fields of tables that represent different elements or items associated with emergy flows, including the annual emergy flow and type, measurement units, and unit emergy values (UEV), along with their bibliographic references. In comparison, the geoinformatics module used for evaluating scenarios also provides an emergy table (Appendix A), where the UEV and its bibliographic references are represented by the coefficients $C_{1}$ to $C_{4}$. The annual flow is determined by a function with measurement units equal to the monthly water flow ( $\mathrm{m}^{3} / \mathrm{month}$ ) for each item. Additionally, the evaluation modules add to the emergy tables alternate coefficients $C_{2 \mathrm{e}}$ to $C_{4 \mathrm{e}}\left(\mathrm{C}_{1 \mathrm{e}}=0\right.$ for each case) for estimat- 
Table 3

Emergy coefficients of water supply processes in the UCLR basin.

\begin{tabular}{|c|c|c|c|c|c|}
\hline Process & & $\mathrm{C}_{1}$ & $\mathrm{C}_{2}$ & $\mathrm{C}_{3}$ & $\mathrm{C}_{4}$ \\
\hline \multirow[t]{3}{*}{ Deep Wells } & Average & $2.94 \mathrm{E}+14$ & $5.34 \mathrm{E}+10$ & $2.33 \mathrm{E}+05$ & $1.75 \mathrm{E}-02$ \\
\hline & Standard deviation & $1.68 \mathrm{E}+14$ & $1.79 E+10$ & $2.15 E+05$ & $2.98 \mathrm{E}-02$ \\
\hline & Median & $2.15 E+14$ & $5.26 \mathrm{E}+10$ & $1.58 \mathrm{E}+05$ & $9.83 \mathrm{E}-03$ \\
\hline \multirow[t]{3}{*}{ WWTP } & Average & $1.18 \mathrm{E}+17$ & $7.28 \mathrm{E}+12$ & 0 & 0 \\
\hline & Standard deviation & $2.65 E+17$ & $1.58 \mathrm{E}+13$ & 0 & 0 \\
\hline & Median & $3.04 \mathrm{E}+16$ & $1.99 \mathrm{E}+11$ & 0 & 0 \\
\hline \multirow[t]{3}{*}{ Imported water } & Average & 0 & $2.31 \mathrm{E}+12$ & 0 & 0 \\
\hline & Standard deviation & 0 & 0 & 0 & 0 \\
\hline & Median & 0 & $2.31 \mathrm{E}+12$ & 0 & 0 \\
\hline
\end{tabular}

WWTP: Wastewater treatment plants.

The emergy function has the shape: $\mathrm{Em}=\mathrm{C}_{1}+\mathrm{C}_{2} \mathrm{x}+\mathrm{C}_{3} \mathrm{x}^{2}+\mathrm{C}_{4} \mathrm{x}^{3}$

where Em: emergy (sej/month) and $\mathrm{x}$ : associated water flow rate with an arc $\left(\mathrm{m}^{3} / \mathrm{month}\right)$

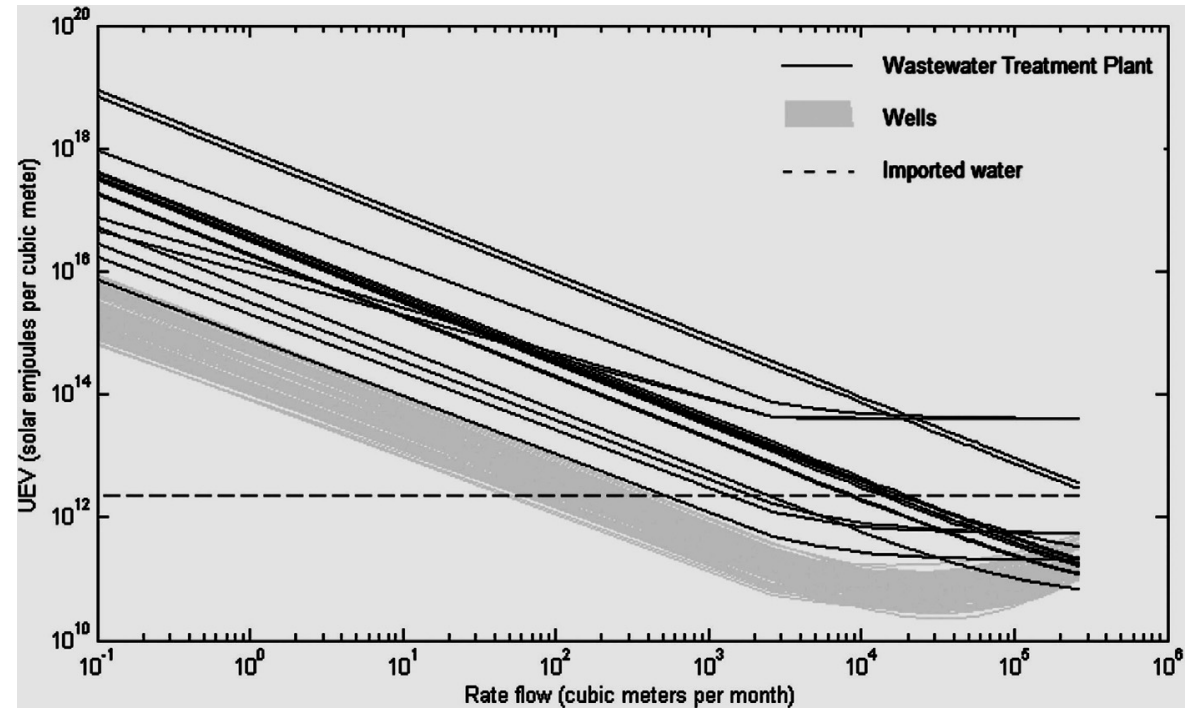

Fig. 7. UEV by type of supply process in the UCLR basin.

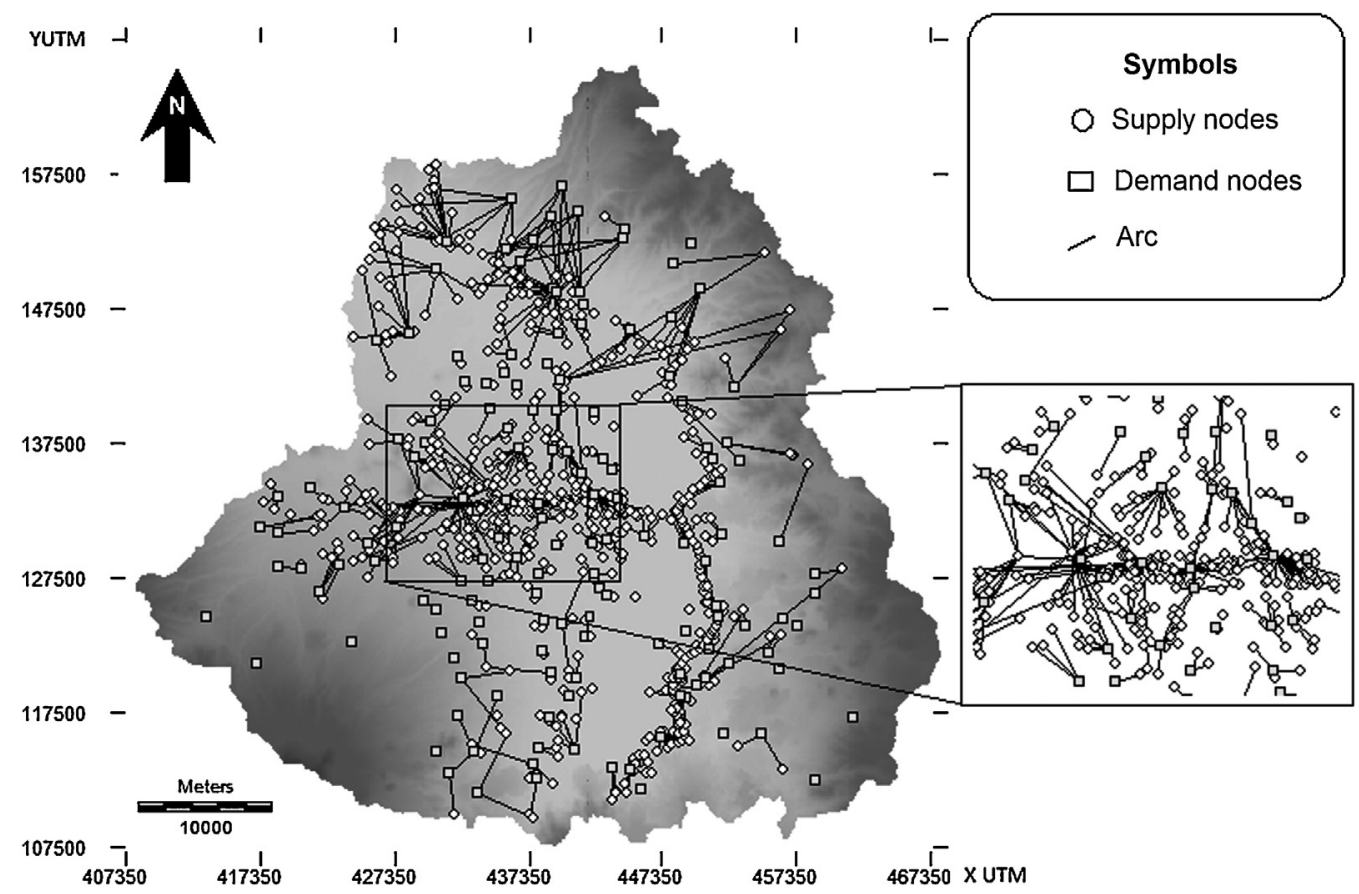

Fig. 8. Current framework of the supply-demand nodes network (scenario CSC). 
Table 4

Annual allocation of water for evaluated scenarios.

\begin{tabular}{|c|c|c|c|c|c|c|c|c|}
\hline \multicolumn{2}{|c|}{ Scenario } & \multirow[t]{2}{*}{ Demand } & \multicolumn{4}{|l|}{ Supply sources } & \multirow[t]{2}{*}{ Total } & \multirow[t]{2}{*}{ Deficit } \\
\hline & & & Groundwater & Surface water & Imported water & Recycled water & & \\
\hline \multirow[t]{3}{*}{0} & Dry & 280.64 & 90.90 & 21.87 & 26.74 & 0.00 & 139.51 & $50.29 \%$ \\
\hline & Mean & 200.24 & 89.34 & 13.11 & 26.74 & 0.00 & 129.19 & $35.48 \%$ \\
\hline & Wet & 167.87 & 76.02 & 10.11 & 26.74 & 0.00 & 112.87 & $32.76 \%$ \\
\hline \multirow[t]{3}{*}{1} & Dry & 280.64 & 114.89 & 20.92 & 1.89 & 26.59 & 164.29 & $41.46 \%$ \\
\hline & Mean & 200.24 & 114.86 & 13.11 & 1.89 & 16.15 & 146.01 & $27.08 \%$ \\
\hline & Wet & 167.87 & 113.60 & 10.31 & 1.89 & 12.74 & 138.54 & $17.47 \%$ \\
\hline \multirow[t]{3}{*}{2} & Dry & 280.64 & 114.89 & 20.92 & 1.89 & 27.46 & 165.16 & $41.15 \%$ \\
\hline & Mean & 200.24 & 114.86 & 13.11 & 1.89 & 17.05 & 146.91 & $26.64 \%$ \\
\hline & Wet & 167.87 & 113.60 & 10.31 & 1.89 & 13.74 & 139.54 & $16.88 \%$ \\
\hline \multirow[t]{3}{*}{3} & Dry & 280.64 & 114.89 & 20.92 & 1.89 & 28.71 & 166.41 & $40.70 \%$ \\
\hline & Mean & 200.24 & 114.86 & 13.11 & 1.89 & 19.35 & 149.21 & $25.49 \%$ \\
\hline & Wet & 167.87 & 113.60 & 10.31 & 1.89 & 15.14 & 140.94 & $16.04 \%$ \\
\hline
\end{tabular}

Units in $\mathrm{hm}^{3} /$ year.

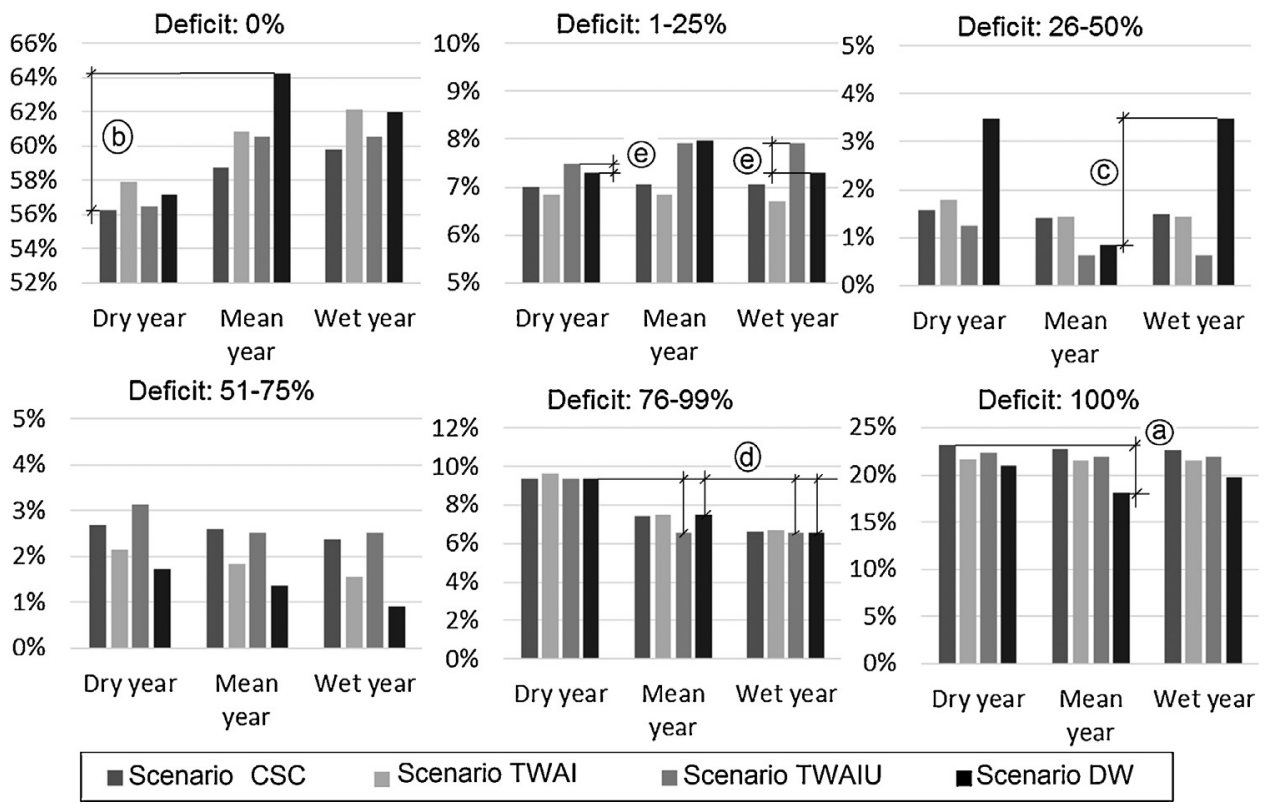

Fig. 9. Associated percentage of nodes surpassing the threshold of average monthly deficit.

ing the flow associated with the energy consumption $(\mathrm{J} /$ month $)$ in the corresponding items.

In this way, the emergy tables for each of the 117 demand nodes can be observed in the generated databases. In these, it can be observed that the agricultural demand nodes are affected by variation in hydrological conditions. For example, Tables 5 and 6, show the emergy accounting for one of these nodes (identifier 1602 in the database) during the month of July for scenarios CSC and TWAIU, respectively. For scenario CSC, the flows in emergy and energy, in addition to the ESI, are maintained constant in relationship to the variation in the hydrological conditions resulting from the lack of capacity of the supply nodes to administer more water. Due to this, the deficit increases by $69 \%$ for a wet year and up to $91 \%$ for a dry year.

To the contrary, in scenario TWAIU the emergy flow must increase by $3 \%$ in order to decrease the water deficit by $64 \%$ and $38 \%$ for a dry and average year, respectively. For a wet year, the water demand is completely covered, even resulting in a decreasing emergy flow due to the substitution of water supplied from wells with recycled water. A double-count of emergy due to the infrastructure of the system was avoided, as the module recognized the first instance of a source and omitted this value $\left(C_{1}\right)$ in later arcs.
In scenario TWAIU, the water supply from wastewater treatment plants leads to an increase in the emergy flow in the form of economic feedback (F). In transitioning from scenario CSC to scenario TWAI, a decrease in the ESI is implied in order to decrease the deficit. In this case, the least favorable case for nodes is a dry year, where for each decrease in percentage point of the deficit, the ESI will also be reduced by 0.13 . For average and wet years, the decrease in ESI is by 0.07 and 0.05 , respectively.

Both annually and overall, scenario CSC has weighted UEV averages of $4.8 \times 10^{13}, 5.1 \times 10^{13}$ and $5.3 \times 10^{13} \mathrm{seJ} / \mathrm{m}^{3}$, corresponding to the delivered water volumes for a dry, average, and wet year, respectively. For the same water regimens, scenarios TWAI, TWAIU, and DW present values of $5.2 \times 10^{13}, 5.8 \times 10^{13}$, and $6.0 \times 10^{13} \mathrm{seJ} / \mathrm{m}^{3}$ without significant variation.

The ESI does not present significant variations given the differing scenarios, but variation may be observed in the proportion of nodes that correspond to each ESI threshold described beforehand, which differ for the four described infrastructure scenarios for water supply (Fig. 10). The lowest sustainability threshold (ESI = 0) on scenario CSC had the greatest percentage (greater than 50\%) of nodes that did not utilize renewable resources, while scenarios TWAIU and DW reduced this percentage by up to $46 \%$ between April and 
Table 5

Emergy table of an agricultural water demand node for July in the scenario 0 .

\begin{tabular}{|c|c|c|c|c|c|c|c|c|c|c|c|c|c|c|}
\hline \multirow[t]{2}{*}{ Source ID } & \multirow[t]{2}{*}{ Source description } & \multirow[t]{2}{*}{ Input element } & \multicolumn{4}{|l|}{ Dry year } & \multicolumn{4}{|l|}{ Mean year } & \multicolumn{4}{|l|}{ Wet year } \\
\hline & & & Flow & Emergy & $\mathrm{T}$ & Energy & Flow & Emergy & $\mathrm{T}$ & Energy & Flow & Emergy & $\mathrm{T}$ & Energy \\
\hline Demand & & & -700000 & & & & -400000 & & & & -200000 & & & \\
\hline 10 & Deep well & Energy & 3115.84 & $1.9 \mathrm{E}+14$ & $\mathrm{~F}$ & $1.9 \mathrm{E}+09$ & 3115.84 & $1.9 \mathrm{E}+14$ & $\mathrm{~F}$ & $1.9 \mathrm{E}+09$ & 3115.84 & $1.9 \mathrm{E}+14$ & $\mathrm{~F}$ & $1.9 \mathrm{E}+09$ \\
\hline 10 & Deep well & Water & 26.31 & $1.9 \mathrm{E}+15$ & $\mathrm{R}$ & $0.0 \mathrm{E}+00$ & 26.31 & $1.9 \mathrm{E}+15$ & $\mathrm{R}$ & $0.0 \mathrm{E}+00$ & 26.31 & $1.9 \mathrm{E}+15$ & $\mathrm{R}$ & $0.0 \mathrm{E}+00$ \\
\hline 10 & Deep well & Infrastructure & 26.31 & $7.6 \mathrm{E}+13$ & $\mathrm{~F}$ & $0.0 \mathrm{E}+00$ & 26.31 & $7.6 \mathrm{E}+13$ & $\mathrm{~F}$ & $0.0 \mathrm{E}+00$ & 26.31 & $7.6 \mathrm{E}+13$ & F & $0.0 \mathrm{E}+00$ \\
\hline 10 & Deep well & Energy & 26.31 & $1.6 \mathrm{E}+12$ & $\mathrm{~F}$ & $1.6 \mathrm{E}+07$ & 26.31 & $1.6 \mathrm{E}+12$ & $\mathrm{~F}$ & $1.6 \mathrm{E}+07$ & 26.31 & $1.6 \mathrm{E}+12$ & F & $1.6 \mathrm{E}+07$ \\
\hline 10 & Deep well & Water & 3115.84 & $2.2 \mathrm{E}+17$ & $\mathrm{~N}$ & $0.0 \mathrm{E}+00$ & 3115.84 & $2.2 \mathrm{E}+17$ & $\mathrm{~N}$ & $0.0 \mathrm{E}+00$ & 3115.84 & $2.2 \mathrm{E}+17$ & $\mathrm{~N}$ & $0.0 \mathrm{E}+00$ \\
\hline 10 & Deep well & Infrastructure & 3115.84 & $0.0 \mathrm{E}+00$ & $\mathrm{~F}$ & $0.0 \mathrm{E}+00$ & 3115.84 & $0.0 \mathrm{E}+00$ & $\mathrm{~F}$ & $0.0 \mathrm{E}+00$ & 3115.84 & $0.0 \mathrm{E}+00$ & $\mathrm{~F}$ & $0.0 \mathrm{E}+00$ \\
\hline 27 & Deep well & Energy & 5435.94 & $1.9 \mathrm{E}+14$ & $\mathrm{~F}$ & $1.9 \mathrm{E}+09$ & 5435.94 & $1.9 \mathrm{E}+14$ & $\mathrm{~F}$ & $1.9 \mathrm{E}+09$ & 5435.94 & $1.9 \mathrm{E}+14$ & $\mathrm{~F}$ & $1.9 \mathrm{E}+09$ \\
\hline 27 & Deep well & Infrastructure & 5435.94 & $0.0 \mathrm{E}+00$ & $\mathrm{~F}$ & $0.0 \mathrm{E}+00$ & 5435.94 & $0.0 \mathrm{E}+00$ & $\mathrm{~F}$ & $0.0 \mathrm{E}+00$ & 5435.94 & $0.0 \mathrm{E}+00$ & $\mathrm{~F}$ & $0.0 \mathrm{E}+00$ \\
\hline 27 & Deep well & Water & 5435.94 & $3.9 E+17$ & $\mathrm{~N}$ & $0.0 \mathrm{E}+00$ & 5435.94 & $3.9 \mathrm{E}+17$ & $\mathrm{~N}$ & $0.0 \mathrm{E}+00$ & 5435.94 & $3.9 E+17$ & $\mathrm{~N}$ & $0.0 \mathrm{E}+00$ \\
\hline 27 & Deep well & Energy & 87.28 & $3.0 \mathrm{E}+12$ & $\mathrm{~F}$ & $3.0 \mathrm{E}+07$ & 87.28 & $3.0 \mathrm{E}+12$ & $\mathrm{~F}$ & $3.0 \mathrm{E}+07$ & 87.28 & $3.0 \mathrm{E}+12$ & F & $3.0 \mathrm{E}+07$ \\
\hline 27 & Deep well & Water & 87.28 & $6.2 \mathrm{E}+15$ & $\mathrm{R}$ & $0.0 \mathrm{E}+00$ & 87.28 & $6.2 \mathrm{E}+15$ & $\mathrm{R}$ & $0.0 \mathrm{E}+00$ & 87.28 & $6.2 \mathrm{E}+15$ & $\mathrm{R}$ & $0.0 \mathrm{E}+00$ \\
\hline 27 & Deep well & Infrastructure & 87.28 & $2.1 \mathrm{E}+14$ & $\mathrm{~F}$ & $0.0 \mathrm{E}+00$ & 87.28 & $2.1 \mathrm{E}+14$ & $\mathrm{~F}$ & $0.0 \mathrm{E}+00$ & 87.28 & $2.1 \mathrm{E}+14$ & F & $0.0 \mathrm{E}+00$ \\
\hline 172 & Deep well & Infrastructure & 34.08 & $3.1 \mathrm{E}+14$ & $\mathrm{~F}$ & $0.0 \mathrm{E}+00$ & 34.08 & $3.1 \mathrm{E}+14$ & $\mathrm{~F}$ & $0.0 \mathrm{E}+00$ & 34.08 & $3.1 \mathrm{E}+14$ & $\mathrm{~F}$ & $0.0 \mathrm{E}+00$ \\
\hline 172 & Deep well & Water & 34.08 & $2.4 \mathrm{E}+15$ & $\mathrm{R}$ & $0.0 \mathrm{E}+00$ & 34.08 & $2.4 \mathrm{E}+15$ & $\mathrm{R}$ & $0.0 \mathrm{E}+00$ & 34.08 & $2.4 \mathrm{E}+15$ & $\mathrm{R}$ & $0.0 \mathrm{E}+00$ \\
\hline 172 & Deep well & Energy & 49248.00 & $2.2 \mathrm{E}+15$ & $\mathrm{~F}$ & $3.9 \mathrm{E}+10$ & 49248.00 & $2.2 \mathrm{E}+15$ & $\mathrm{~F}$ & $3.9 \mathrm{E}+10$ & 49248.00 & $2.2 E+15$ & $\mathrm{~F}$ & $3.9 \mathrm{E}+10$ \\
\hline 172 & Deep well & Energy & 34.08 & $1.3 \mathrm{E}+12$ & $\mathrm{~F}$ & $2.4 \mathrm{E}+07$ & 34.08 & $1.3 \mathrm{E}+12$ & $\mathrm{~F}$ & $2.4 \mathrm{E}+07$ & 34.08 & $1.3 E+12$ & F & $2.4 \mathrm{E}+07$ \\
\hline 172 & Deep well & Infrastructure & 49248.00 & $0.0 \mathrm{E}+00$ & $\mathrm{~F}$ & $0.0 \mathrm{E}+00$ & 49248.00 & $0.0 \mathrm{E}+00$ & $\mathrm{~F}$ & $0.0 \mathrm{E}+00$ & 49248.00 & $0.0 \mathrm{E}+00$ & $\mathrm{~F}$ & $0.0 \mathrm{E}+00$ \\
\hline 172 & Deep well & Water & 49248.00 & $3.5 \mathrm{E}+18$ & $\mathrm{~N}$ & $0.0 \mathrm{E}+00$ & 49248.00 & $3.5 E+18$ & $\mathrm{~N}$ & $0.0 \mathrm{E}+00$ & 49248.00 & $3.5 \mathrm{E}+18$ & $\mathrm{~N}$ & $0.0 \mathrm{E}+00$ \\
\hline 176 & Deep well & Water & 48.93 & $3.5 \mathrm{E}+15$ & $\mathrm{R}$ & $0.0 \mathrm{E}+00$ & 48.93 & $3.5 E+15$ & $\mathrm{R}$ & $0.0 \mathrm{E}+00$ & 48.93 & $3.5 \mathrm{E}+15$ & $\mathrm{R}$ & $0.0 \mathrm{E}+00$ \\
\hline 176 & Deep well & Infrastructure & 48.93 & $3.3 E+14$ & $\mathrm{~F}$ & $0.0 \mathrm{E}+00$ & 48.93 & $3.3 \mathrm{E}+14$ & $\mathrm{~F}$ & $0.0 \mathrm{E}+00$ & 48.93 & $3.3 E+14$ & $\mathrm{~F}$ & $0.0 \mathrm{E}+00$ \\
\hline 176 & Deep well & Energy & 48.93 & $1.9 \mathrm{E}+12$ & $\mathrm{~F}$ & $3.7 E+07$ & 48.93 & $1.9 \mathrm{E}+12$ & $\mathrm{~F}$ & $3.7 \mathrm{E}+07$ & 48.93 & $1.9 \mathrm{E}+12$ & $\mathrm{~F}$ & $3.7 E+07$ \\
\hline 176 & Deep well & Water & 2561.96 & $1.8 \mathrm{E}+17$ & $\mathrm{~N}$ & $0.0 \mathrm{E}+00$ & 2561.96 & $1.8 \mathrm{E}+17$ & $\mathrm{~N}$ & $0.0 \mathrm{E}+00$ & 2561.96 & $1.8 \mathrm{E}+17$ & $\mathrm{~N}$ & $0.0 \mathrm{E}+00$ \\
\hline 176 & Deep well & Infrastructure & 2561.96 & $0.0 \mathrm{E}+00$ & $\mathrm{~F}$ & $0.0 \mathrm{E}+00$ & 2561.96 & $0.0 \mathrm{E}+00$ & $\mathrm{~F}$ & $0.0 \mathrm{E}+00$ & 2561.96 & $0.0 \mathrm{E}+00$ & F & $0.0 \mathrm{E}+00$ \\
\hline 176 & Deep well & Energy & 2561.96 & $9.9 \mathrm{E}+13$ & $\mathrm{~F}$ & $1.9 \mathrm{E}+09$ & 2561.96 & $9.9 \mathrm{E}+13$ & $\mathrm{~F}$ & $1.9 \mathrm{E}+09$ & 2561.96 & $9.9 \mathrm{E}+13$ & F & $1.9 \mathrm{E}+09$ \\
\hline 177 & Deep well & Water & 50.73 & $3.6 \mathrm{E}+15$ & $\mathrm{R}$ & $0.0 \mathrm{E}+00$ & 50.73 & $3.6 \mathrm{E}+15$ & $\mathrm{R}$ & $0.0 \mathrm{E}+00$ & 50.73 & $3.6 \mathrm{E}+15$ & $\mathrm{R}$ & $0.0 \mathrm{E}+00$ \\
\hline 177 & Deep well & Infrastructure & 50.73 & $3.3 E+14$ & $\mathrm{~F}$ & $0.0 \mathrm{E}+00$ & 50.73 & $3.3 E+14$ & $\mathrm{~F}$ & $0.0 \mathrm{E}+00$ & 50.73 & $3.3 E+14$ & $\mathrm{~F}$ & $0.0 \mathrm{E}+00$ \\
\hline 177 & Deep well & Energy & 50.73 & $1.9 \mathrm{E}+12$ & $\mathrm{~F}$ & $5.7 \mathrm{E}+07$ & 50.73 & $1.9 \mathrm{E}+12$ & $\mathrm{~F}$ & $5.7 \mathrm{E}+07$ & 50.73 & $1.9 \mathrm{E}+12$ & $\mathrm{~F}$ & $5.7 E+07$ \\
\hline 177 & Deep well & Water & 1717.33 & $1.2 \mathrm{E}+17$ & $\mathrm{~N}$ & $0.0 \mathrm{E}+00$ & 1717.33 & $1.2 \mathrm{E}+17$ & $\mathrm{~N}$ & $0.0 \mathrm{E}+00$ & 1717.33 & $1.2 E+17$ & $\mathrm{~N}$ & $0.0 \mathrm{E}+00$ \\
\hline 177 & Deep well & Infrastructure & 1717.33 & $0.0 \mathrm{E}+00$ & $\mathrm{~F}$ & $0.0 \mathrm{E}+00$ & 1717.33 & $0.0 \mathrm{E}+00$ & $\mathrm{~F}$ & $0.0 \mathrm{E}+00$ & 1717.33 & $0.0 \mathrm{E}+00$ & $\mathrm{~F}$ & $0.0 \mathrm{E}+00$ \\
\hline 177 & Deep well & Energy & 1717.33 & $6.4 \mathrm{E}+13$ & $\mathrm{~F}$ & $1.9 \mathrm{E}+09$ & 1717.33 & $6.4 \mathrm{E}+13$ & $\mathrm{~F}$ & $1.9 \mathrm{E}+09$ & 1717.33 & $6.4 \mathrm{E}+13$ & $\mathrm{~F}$ & $1.9 \mathrm{E}+09$ \\
\hline Total & & & & $4.4 \mathrm{E}+18$ & & $4.7 \mathrm{E}+10$ & & $4.4 \mathrm{E}+18$ & & $4.7 \mathrm{E}+10$ & & $4.4 \mathrm{E}+18$ & & $4.7 \mathrm{E}+10$ \\
\hline Deficit & & & $-6.4 \mathrm{E}+05$ & & & & $-3.4 \mathrm{E}+05$ & & & & $-1.4 \mathrm{E}+05$ & & & \\
\hline Deficit proportional & & & 0.91 & & & & 0.84 & & & & 0.69 & & & \\
\hline ESI & & & 4.40 & & & & 4.40 & & & & 4.40 & & & \\
\hline
\end{tabular}

T: Type of emergy flow ( $\mathrm{R}=$ Renewable, $\mathrm{N}=$ Non-renewable, $\mathrm{F}=$ Feedback) ESI: Environmental Sustainable Index

Flow and Deficit: $\mathrm{m}^{3} /$ month, Emergy: sej/month, Energy: J/month. 
Table 6

Emergy table of an agricultural water demand node for July in the scenario 2.

\begin{tabular}{|c|c|c|c|c|c|c|c|c|c|c|c|c|c|c|}
\hline \multirow[t]{2}{*}{ Source ID } & \multirow[t]{2}{*}{ Source description } & \multirow[t]{2}{*}{ Input element } & \multicolumn{4}{|l|}{ Dry year } & \multicolumn{4}{|l|}{ Mean year } & \multicolumn{4}{|l|}{ Wet year } \\
\hline & & & Flow & Emergy & $\mathrm{T}$ & Energy & Flow & Emergy & $\mathrm{T}$ & Energy & Flow & Emergy & $\mathrm{T}$ & Energy \\
\hline Demand & & & -700000 & & & & -400000 & & & & -200000 & & & \\
\hline 10 & Deep well & Water & 26.31 & $1.9 \mathrm{E}+15$ & $\mathrm{R}$ & $0.0 \mathrm{E}+00$ & 2561.96 & $9.9 \mathrm{E}+13$ & $\mathrm{~F}$ & $1.9 \mathrm{E}+09$ & 26.31 & $1.9 \mathrm{E}+15$ & $\mathrm{R}$ & $0.0 \mathrm{E}+00$ \\
\hline 10 & Deep well & Infrastructure & 26.31 & $7.6 \mathrm{E}+13$ & $\mathrm{~F}$ & $0.0 \mathrm{E}+00$ & 50.73 & $3.6 \mathrm{E}+15$ & $\mathrm{R}$ & $0.0 \mathrm{E}+00$ & 26.31 & $7.6 E+13$ & $\mathrm{~F}$ & $0.0 \mathrm{E}+00$ \\
\hline 10 & Deep well & Energy & 26.31 & $1.6 \mathrm{E}+12$ & $\mathrm{~F}$ & $1.6 \mathrm{E}+07$ & 50.73 & $3.3 \mathrm{E}+14$ & $\mathrm{~F}$ & $0.0 \mathrm{E}+00$ & 26.31 & $1.6 \mathrm{E}+12$ & $\mathrm{~F}$ & $1.6 \mathrm{E}+07$ \\
\hline 10 & Deep well & Water & 3115.84 & $2.2 \mathrm{E}+17$ & $\mathrm{~N}$ & $0.0 \mathrm{E}+00$ & 50.73 & $1.9 \mathrm{E}+12$ & $\mathrm{~F}$ & $5.7 \mathrm{E}+07$ & 3115.84 & $2.2 \mathrm{E}+17$ & $\mathrm{~N}$ & $0.0 \mathrm{E}+00$ \\
\hline 10 & Deep well & Infrastructure & 3115.84 & $0.0 \mathrm{E}+00$ & $\mathrm{~F}$ & $0.0 \mathrm{E}+00$ & 1717.33 & $1.2 \mathrm{E}+17$ & $\mathrm{~N}$ & $0.0 \mathrm{E}+00$ & 3115.84 & $0.0 \mathrm{E}+00$ & $\mathrm{~F}$ & $0.0 \mathrm{E}+00$ \\
\hline 10 & Deep well & Energy & 3115.84 & $1.9 E+14$ & $\mathrm{~F}$ & $1.9 \mathrm{E}+09$ & 1717.33 & $0.0 \mathrm{E}+00$ & $\mathrm{~F}$ & $0.0 \mathrm{E}+00$ & 3115.84 & $1.9 \mathrm{E}+14$ & $\mathrm{~F}$ & $1.9 \mathrm{E}+09$ \\
\hline 27 & Deep well & Water & 87.28 & $6.2 E+15$ & $\mathrm{R}$ & $0.0 \mathrm{E}+00$ & 1717.33 & $6.4 \mathrm{E}+13$ & $\mathrm{~F}$ & $1.9 \mathrm{E}+09$ & 87.28 & $6.2 \mathrm{E}+15$ & $\mathrm{R}$ & $0.0 \mathrm{E}+00$ \\
\hline 27 & Deep well & Infrastructure & 87.28 & $2.1 \mathrm{E}+14$ & $\mathrm{~F}$ & $0.0 \mathrm{E}+00$ & 103680.00 & $3.6 \mathrm{E}+16$ & $\mathrm{R}$ & $0.0 \mathrm{E}+00$ & 87.28 & $2.1 \mathrm{E}+14$ & $\mathrm{~F}$ & $0.0 \mathrm{E}+00$ \\
\hline 27 & Deep well & Energy & 87.28 & $3.0 \mathrm{E}+12$ & $\mathrm{~F}$ & $3.0 \mathrm{E}+07$ & 103680.00 & $4.3 \mathrm{E}+16$ & $\mathrm{~F}$ & $0.0 \mathrm{E}+00$ & 87.28 & $3.0 \mathrm{E}+12$ & $\mathrm{~F}$ & $3.0 \mathrm{E}+07$ \\
\hline 27 & Deep well & Water & 5435.94 & $3.9 E+17$ & $\mathrm{~N}$ & $0.0 \mathrm{E}+00$ & 103680.00 & $5.0 \mathrm{E}+15$ & $\mathrm{~F}$ & $6.7 \mathrm{E}+10$ & 5435.94 & $3.9 E+17$ & $\mathrm{~N}$ & $0.0 \mathrm{E}+00$ \\
\hline 27 & Deep well & Infrastructure & 5435.94 & $0.0 \mathrm{E}+00$ & $\mathrm{~F}$ & $0.0 \mathrm{E}+00$ & 82944.00 & $2.9 \mathrm{E}+16$ & $\mathrm{R}$ & $0.0 \mathrm{E}+00$ & 5435.94 & $0.0 \mathrm{E}+00$ & $\mathrm{~F}$ & $0.0 \mathrm{E}+00$ \\
\hline 27 & Deep well & Energy & 5435.94 & $1.9 E+14$ & $\mathrm{~F}$ & $1.9 \mathrm{E}+09$ & 82944.00 & $3.5 \mathrm{E}+16$ & $\mathrm{~F}$ & $0.0 \mathrm{E}+00$ & 5435.94 & $1.9 \mathrm{E}+14$ & $\mathrm{~F}$ & $1.9 \mathrm{E}+09$ \\
\hline 172 & Deep well & Water & 34.08 & $2.4 \mathrm{E}+15$ & $\mathrm{R}$ & $0.0 \mathrm{E}+00$ & 82944.00 & $4.0 \mathrm{E}+15$ & $\mathrm{~F}$ & $5.3 E+10$ & 34.08 & $2.4 \mathrm{E}+15$ & $\mathrm{R}$ & $0.0 \mathrm{E}+00$ \\
\hline 172 & Deep well & Infrastructure & 34.08 & $3.1 \mathrm{E}+14$ & $\mathrm{~F}$ & $0.0 \mathrm{E}+00$ & 26.31 & $1.9 \mathrm{E}+15$ & $\mathrm{R}$ & $0.0 \mathrm{E}+00$ & 34.08 & $3.1 \mathrm{E}+14$ & $\mathrm{~F}$ & $0.0 \mathrm{E}+00$ \\
\hline 172 & Deep well & Energy & 34.08 & $1.3 \mathrm{E}+12$ & $\mathrm{~F}$ & $2.4 \mathrm{E}+07$ & 26.31 & $7.6 E+13$ & $\mathrm{~F}$ & $0.0 \mathrm{E}+00$ & 34.08 & $1.3 \mathrm{E}+12$ & $\mathrm{~F}$ & $2.4 \mathrm{E}+07$ \\
\hline 172 & Deep well & Water & 49248.00 & $3.5 E+18$ & $\mathrm{~N}$ & $0.0 \mathrm{E}+00$ & 26.31 & $1.6 \mathrm{E}+12$ & $\mathrm{~F}$ & $1.6 \mathrm{E}+07$ & 297.60 & $2.1 \mathrm{E}+16$ & $\mathrm{~N}$ & $0.0 \mathrm{E}+00$ \\
\hline 172 & Deep well & Infrastructure & 49248.00 & $0.0 \mathrm{E}+00$ & $\mathrm{~F}$ & $0.0 \mathrm{E}+00$ & 3115.84 & $2.2 \mathrm{E}+17$ & $\mathrm{~N}$ & $0.0 \mathrm{E}+00$ & 297.60 & $0.0 \mathrm{E}+00$ & $\mathrm{~F}$ & $0.0 \mathrm{E}+00$ \\
\hline 172 & Deep well & Energy & 49248.00 & $2.2 \mathrm{E}+15$ & $\mathrm{~F}$ & $3.9 \mathrm{E}+10$ & 3115.84 & $0.0 \mathrm{E}+00$ & $\mathrm{~F}$ & $0.0 \mathrm{E}+00$ & 297.60 & $1.1 \mathrm{E}+13$ & $\mathrm{~F}$ & $2.1 \mathrm{E}+08$ \\
\hline 176 & Deep well & Water & 48.93 & $3.5 E+15$ & $\mathrm{R}$ & $0.0 \mathrm{E}+00$ & 3115.84 & $1.9 \mathrm{E}+14$ & $\mathrm{~F}$ & $1.9 \mathrm{E}+09$ & 48.93 & $3.5 \mathrm{E}+15$ & $\mathrm{R}$ & $0.0 \mathrm{E}+00$ \\
\hline 176 & Deep well & Infrastructure & 48.93 & $3.3 E+14$ & $\mathrm{~F}$ & $0.0 \mathrm{E}+00$ & 87.28 & $6.2 \mathrm{E}+15$ & $\mathrm{R}$ & $0.0 \mathrm{E}+00$ & 48.93 & $3.3 E+14$ & $\mathrm{~F}$ & $0.0 \mathrm{E}+00$ \\
\hline 176 & Deep well & Energy & 48.93 & $1.9 \mathrm{E}+12$ & $\mathrm{~F}$ & $3.7 E+07$ & 87.28 & $2.1 \mathrm{E}+14$ & $\mathrm{~F}$ & $0.0 \mathrm{E}+00$ & 48.93 & $1.9 \mathrm{E}+12$ & $\mathrm{~F}$ & $3.7 \mathrm{E}+07$ \\
\hline 176 & Deep well & Water & 2561.96 & $1.8 \mathrm{E}+17$ & $\mathrm{~N}$ & $0.0 \mathrm{E}+00$ & 87.28 & $3.0 \mathrm{E}+12$ & $\mathrm{~F}$ & $3.0 \mathrm{E}+07$ & 2561.96 & $1.8 \mathrm{E}+17$ & $\mathrm{~N}$ & $0.0 \mathrm{E}+00$ \\
\hline 176 & Deep well & Infrastructure & 2561.96 & $0.0 \mathrm{E}+00$ & $\mathrm{~F}$ & $0.0 \mathrm{E}+00$ & 5435.94 & $3.9 \mathrm{E}+17$ & $\mathrm{~N}$ & $0.0 \mathrm{E}+00$ & 2561.96 & $0.0 \mathrm{E}+00$ & $\mathrm{~F}$ & $0.0 \mathrm{E}+00$ \\
\hline 176 & Deep well & Energy & 2561.96 & $9.9 E+13$ & $\mathrm{~F}$ & $1.9 \mathrm{E}+09$ & 5435.94 & $0.0 \mathrm{E}+00$ & $\mathrm{~F}$ & $0.0 \mathrm{E}+00$ & 2561.96 & $9.9 \mathrm{E}+13$ & $\mathrm{~F}$ & $1.9 \mathrm{E}+09$ \\
\hline 177 & Deep well & Water & 50.73 & $3.6 \mathrm{E}+15$ & $\mathrm{R}$ & $0.0 \mathrm{E}+00$ & 5435.94 & $1.9 \mathrm{E}+14$ & $\mathrm{~F}$ & $1.9 E+09$ & 50.73 & $3.6 \mathrm{E}+15$ & $\mathrm{R}$ & $0.0 \mathrm{E}+00$ \\
\hline 177 & Deep well & Infrastructure & 50.73 & $3.3 E+14$ & $\mathrm{~F}$ & $0.0 \mathrm{E}+00$ & 34.08 & $2.4 \mathrm{E}+15$ & $\mathrm{R}$ & $0.0 \mathrm{E}+00$ & 50.73 & $3.3 E+14$ & $\mathrm{~F}$ & $0.0 \mathrm{E}+00$ \\
\hline 177 & Deep well & Energy & 50.73 & $1.9 \mathrm{E}+12$ & $\mathrm{~F}$ & $5.7 \mathrm{E}+07$ & 34.08 & $3.1 \mathrm{E}+14$ & $\mathrm{~F}$ & $0.0 \mathrm{E}+00$ & 50.73 & $1.9 \mathrm{E}+12$ & $\mathrm{~F}$ & $5.7 \mathrm{E}+07$ \\
\hline 177 & Deep well & Water & 1717.33 & $1.2 \mathrm{E}+17$ & $\mathrm{~N}$ & $0.0 \mathrm{E}+00$ & 34.08 & $1.3 \mathrm{E}+12$ & $\mathrm{~F}$ & $2.4 \mathrm{E}+07$ & 1717.33 & $1.2 \mathrm{E}+17$ & $\mathrm{~N}$ & $0.0 \mathrm{E}+00$ \\
\hline 177 & Deep well & Infrastructure & 1717.33 & $0.0 \mathrm{E}+00$ & $\mathrm{~F}$ & $0.0 \mathrm{E}+00$ & 49248.00 & $3.5 E+18$ & $\mathrm{~N}$ & $0.0 \mathrm{E}+00$ & 1717.33 & $0.0 \mathrm{E}+00$ & $\mathrm{~F}$ & $0.0 \mathrm{E}+00$ \\
\hline 177 & Deep well & Energy & 1717.33 & $6.4 E+13$ & $\mathrm{~F}$ & $1.9 \mathrm{E}+09$ & 49248.00 & $0.0 \mathrm{E}+00$ & $\mathrm{~F}$ & $0.0 \mathrm{E}+00$ & 1717.33 & $6.4 E+13$ & $\mathrm{~F}$ & $1.9 \mathrm{E}+09$ \\
\hline 2006 & WWTP & Water & 103680.00 & $3.6 \mathrm{E}+16$ & $\mathrm{R}$ & $0.0 \mathrm{E}+00$ & 49248.00 & $2.2 \mathrm{E}+15$ & $\mathrm{~F}$ & $3.9 \mathrm{E}+10$ & 103680.0 & $3.6 \mathrm{E}+16$ & $\mathrm{R}$ & $0.0 \mathrm{E}+00$ \\
\hline 2006 & WWTP & Infrastructure & 103680.00 & $4.3 E+16$ & $\mathrm{~F}$ & $0.0 \mathrm{E}+00$ & 48.93 & $3.5 \mathrm{E}+15$ & $\mathrm{R}$ & $0.0 \mathrm{E}+00$ & 103680.0 & $4.3 E+16$ & $\mathrm{~F}$ & $0.0 \mathrm{E}+00$ \\
\hline 2006 & WWTP & $\mathrm{E} \& \mathrm{C}$ & 103680.00 & $5.0 \mathrm{E}+15$ & $\mathrm{~F}$ & $6.7 E+10$ & 48.93 & $3.3 \mathrm{E}+14$ & $\mathrm{~F}$ & $0.0 \mathrm{E}+00$ & 103680.0 & $5.0 \mathrm{E}+15$ & $\mathrm{~F}$ & $6.7 \mathrm{E}+10$ \\
\hline 2008 & WWTP & Water & 82944.00 & $2.9 E+16$ & $\mathrm{R}$ & $0.0 \mathrm{E}+00$ & 48.93 & $1.9 \mathrm{E}+12$ & $\mathrm{~F}$ & $3.7 \mathrm{E}+07$ & 82944.00 & $2.9 \mathrm{E}+16$ & $\mathrm{R}$ & $0.0 \mathrm{E}+00$ \\
\hline 2008 & WWTP & Infrastructure & 82944.00 & $3.5 E+16$ & $\mathrm{~F}$ & $0.0 \mathrm{E}+00$ & 2561.96 & $1.8 \mathrm{E}+17$ & $\mathrm{~N}$ & $0.0 \mathrm{E}+00$ & 82944.00 & $3.5 \mathrm{E}+16$ & $\mathrm{~F}$ & $0.0 \mathrm{E}+00$ \\
\hline 2008 & WWTP & $\mathrm{E} \& \mathrm{C}$ & 82944.00 & $4.0 \mathrm{E}+15$ & $\mathrm{~F}$ & $5.3 \mathrm{E}+10$ & 2561.96 & $0.0 \mathrm{E}+00$ & $\mathrm{~F}$ & $0.0 \mathrm{E}+00$ & 82944.00 & $4.0 \mathrm{E}+15$ & $\mathrm{~F}$ & $5.3 \mathrm{E}+10$ \\
\hline Total & & & & $4.6 E+18$ & & $1.7 \mathrm{E}+11$ & & $4.6 \mathrm{E}+18$ & & $1.7 \mathrm{E}+11$ & & $1.1 \mathrm{E}+18$ & & $1.3 \mathrm{E}+11$ \\
\hline Deficit & & & -451049.6 & & & & -151049.6 & & & & 0.00 & & & \\
\hline Deficit proportional & & & 0.64 & & & & 0.38 & & & & 0.00 & & & \\
\hline ESI & & & 0.93 & & & & 0.93 & & & & 1.01 & & & \\
\hline
\end{tabular}

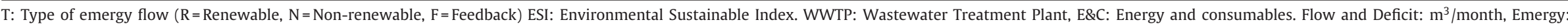
sej/month, Energy: J/month. 

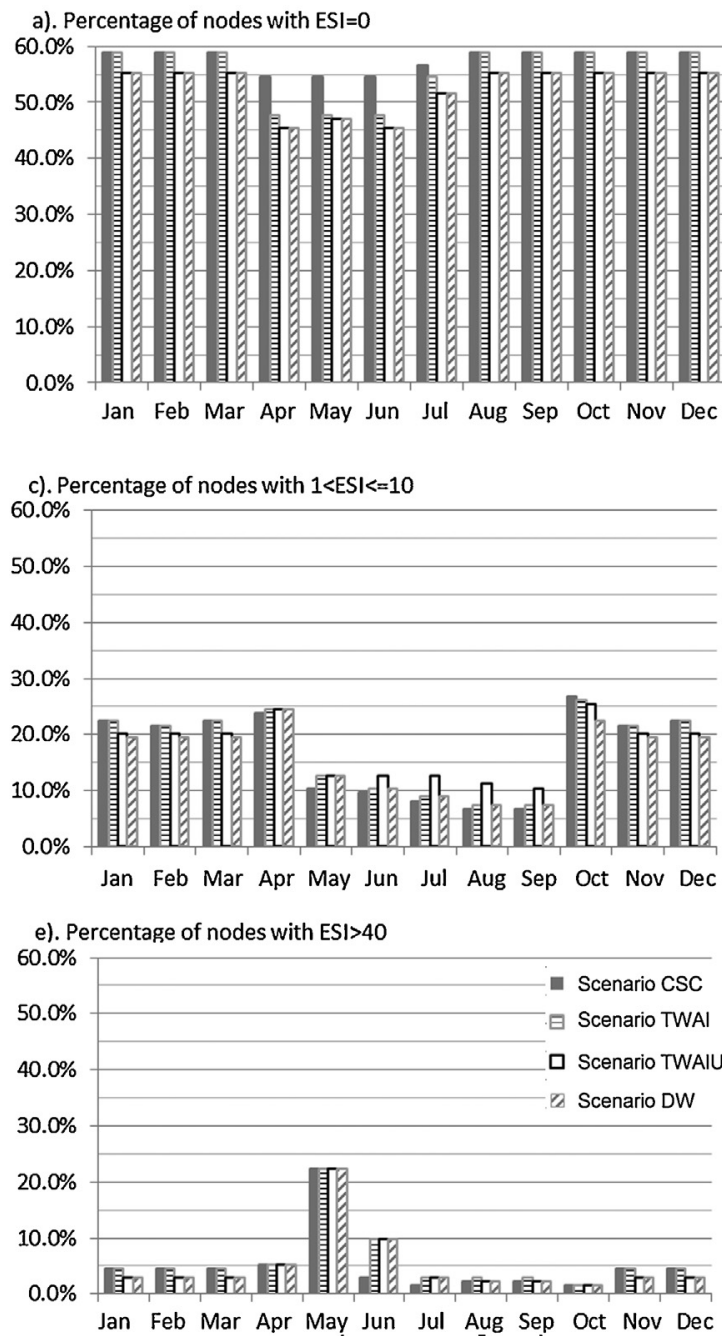

b). Percentage of nodes with $0<E S \mid<=1$
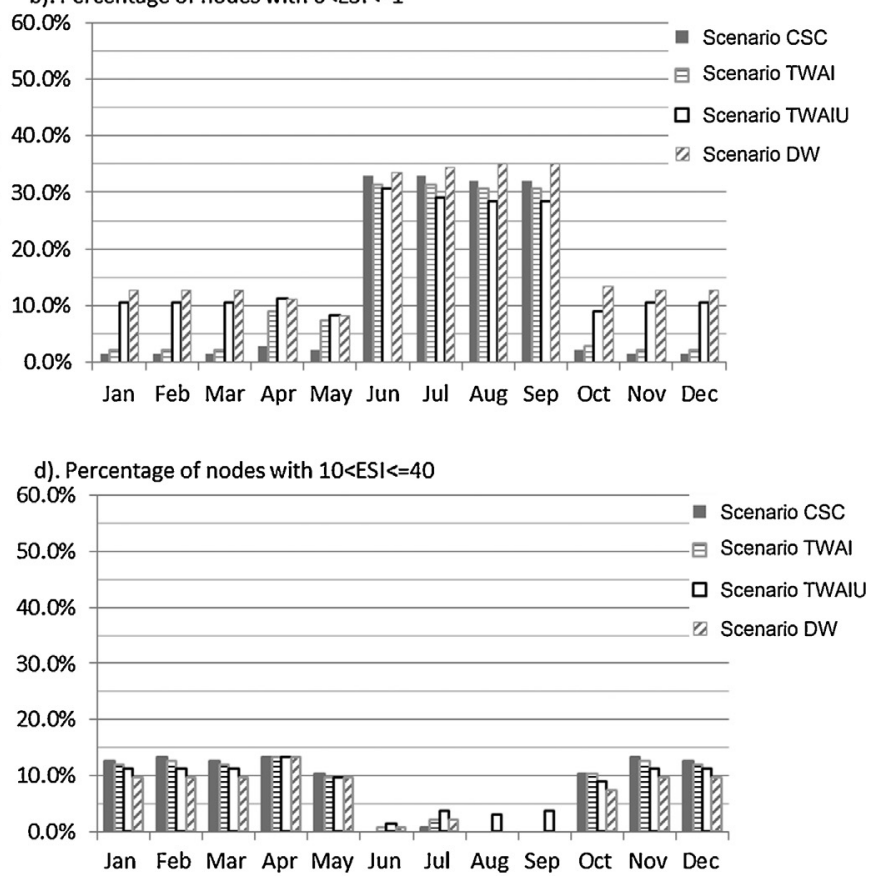

Environmental Sustainability Index (weighted average)

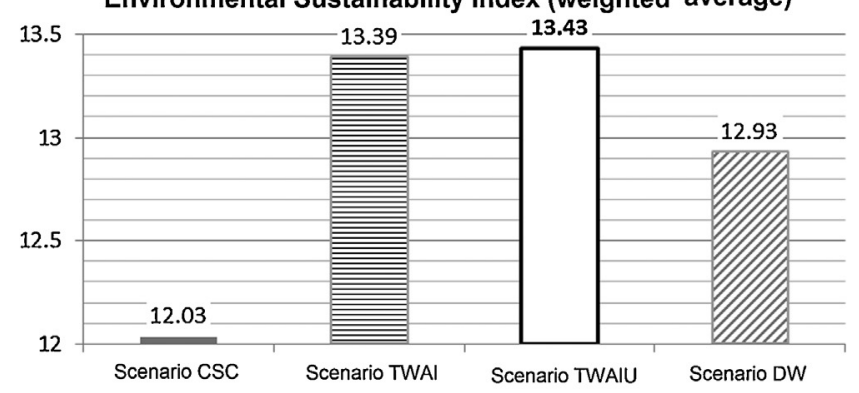

Fig. 10. Monthly Environmental Sustainability Index for the water supply system in the UCLR basin.

June (Fig. 10a). In scenario DW, the majority of nodes have an ESI value between 0 and 1 (Fig. 10b), while in scenario TWAIU these values are contained within the intervals of $1<\mathrm{ESI}<10$ (Fig. 10c) and $10<\mathrm{ESI}<40$ (Fig. 10d), above all for the period of June to September. For ESI $>40$, scenarios TWAIU and DW have the largest proportion of nodes for this interval during June and July and scenarios CSC and TWAI for November to May (Fig. 10e). The weighted average of the ESI with respect to the volume of the water supply to the nodes (Fig. 10f) indicates that scenarios TWAI and TWAIU have the best emergy yield in consideration of inputs from the socioeconomic system, as well as the lowest environmental load.

In evaluating the economic impact (Table 7), scenarios TWAI and TWAIU show significantly less energy consumption in comparison to scenarios CSC and DW, due to the low volume of imported water and a lowered need to treat water for drinking purposes, respectively. In both scenarios TWAI and TWAIU, energy consumption decreases by 10 to $15 \%$ in comparison to scenario CSC, as a function of the water regime, meanwhile the treatment of water to drinkable levels increases energy consumption 1.8 to 3.2 times, with respect to scenario TWAIU.

An almost proportional relationship is maintained between scenarios TWAI and TWAIU. Although scenario TWAIU represents a larger energy consumption than scenario TWAI, the satisfied demand correspondingly increases. In this sense, the economic impacts per supplied cubic meter are equivalent.
The capacity to supply water, represented by the connections between nodes, is an element that also influences the energy consumption. In scenario CSC, the different supply sources are more restricted and as a consequence, the energy consumption varies up to $\mathbf{0 . 3 5 \%}$ from a wet year to a dry year. Scenarios TWAI and TWAIU reflect variations of up to $5.3 \%$ in energy consumption, although scenario DW, with a greater number of supply arcs, demonstrates variations of nearly $60 \%$ across seasons.

Although scenario DW has the lowest values for absolute deficits, scenario TWAIU provides the lowest economic impact and has the highest ESI. Before implementing programs to generate drinking water from wastewater sources (scenario DW, required in the long term), an increase in the efficiency of the processes of the current scenario is feasible. An evolution from scenario CSC to scenario TWAIU is proposed in this study by means of 2 strategies (stage 7 of the methodology; Fig. 2) that would require gradual changes in infrastructure and the eventual reform of policies concerning the allocation of water resources.

The first strategy would involve increasing the supply of renewable resources by means of increasing the capacity of wastewater treatment plants and adapting urban infrastructure in order to recycle water for domestic consumption (toilet and garden use). It may be highlighted that in this scenario, the nodes with $100 \%$ deficit are mainly linked to agricultural demand, which may also imply the use of water supplies from un-registered sources. For the proposed goals, based on the conditions of scenario TWAIU during a 
Table 7

Energy consumption and economic impact due to water supply in the UCLR basin.

\begin{tabular}{|c|c|c|c|c|}
\hline Energy consumption (kWh/year) & Scenario 0 & Scenario 1 & Scenario 2 & Scenario 3 \\
\hline Wet year & 115087197 & 97918810 & 98590648 & 274474706 \\
\hline Mean Year & 115222167 & 99374457 & 100026277 & 328842559 \\
\hline Dry year & 115487016 & 103199255 & 103845401 & 436480107 \\
\hline \multicolumn{5}{|l|}{ Economic impact (USD\$/year) } \\
\hline Wet year & $\$ 12,659,592$ & $\$ 10,771,069$ & $\$ 10,844,971$ & $\$ 30,192,218$ \\
\hline Mean Year & $\$ 12,674,438$ & $\$ 10,931,190$ & $\$ 11,002,890$ & $\$ 36,172,682$ \\
\hline Dry year & $\$ 12,703,572$ & $\$ 11,351,918$ & $\$ 11,422,994$ & $\$ 48,012,812$ \\
\hline \multicolumn{5}{|c|}{ Economic impact per cubic meter (USD $\$ / \mathrm{m}^{3}$ ) } \\
\hline Wet year & $\$ 0.11$ & $\$ 0.08$ & $\$ 0.08$ & $\$ 0.21$ \\
\hline Mean Year & $\$ 0.10$ & $\$ 0.07$ & $\$ 0.07$ & $\$ 0.24$ \\
\hline Dry year & $\$ 0.09$ & $\$ 0.07$ & $\$ 0.07$ & $\$ 0.29$ \\
\hline
\end{tabular}

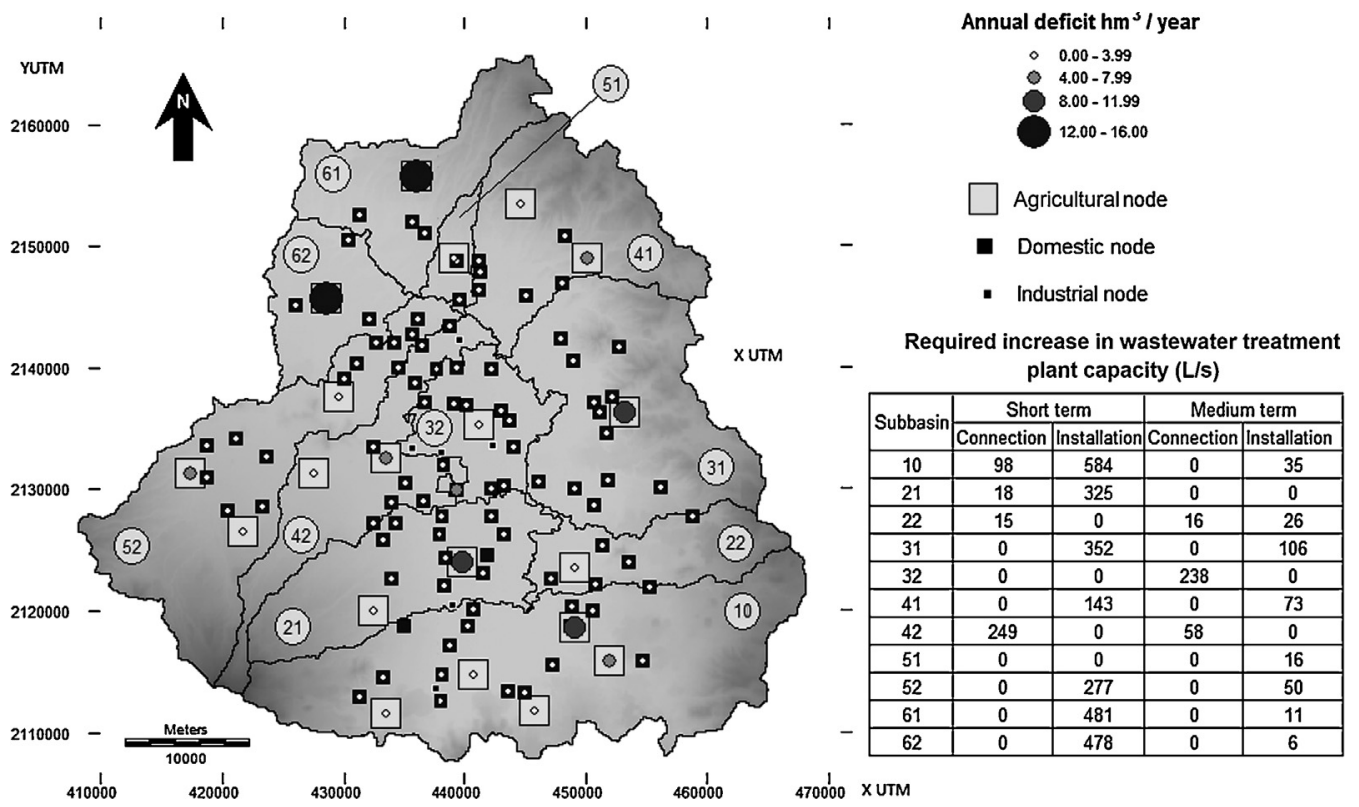

Fig. 11. Annual deficit in water supply (dry year for scenario TWAIU) and additional wastewater treatment capacity required.

dry year, it is possible to re-utilize a water volume of 27.46 out of the $68.4 \mathrm{hm}^{3} /$ year that is treated in WWTP in the watershed. However, due to the geographic location of the WWTP and the configuration of the links between the supply and demand nodes, it is necessary to implement new wastewater treatment plants in strategic places. Thus, the watershed was divided into 11 sub-watersheds (Fig. 11) in order to determine: a) the volume of treated water that can be supplied solely by enabling new connections with existing WWTP and b) the volume of treated water that would require the installation of new infrastructure. In this sense, in the short-term it is proposed that the deficit associated with agricultural demand during a dry year in scenario TWAIU be covered with an additional $12 \mathrm{hm}^{3} /$ year by enabling new links with existing WWTP and $83.2 \mathrm{hm}^{3} /$ year with the installation of new WWTP. In the medium term, the recycling of water for domestic use could achieve a volume of $9.8 \mathrm{hm}^{3} /$ year by enabling links with existing WWTP and may reach $10.2 \mathrm{hm}^{3} /$ year with the construction of new WWTP. Likewise, the proposal to recycle water for domestic use could allocate up to $30 \%$ of the water demand from the domestic nodes corresponding to middle and high socioeconomic areas, thereby leading to a higher ESI value for urban zones, where nodes with ESI $=0$ are concentrated.

In considering these potential re-allocation of water volume, policy reforms must consider the use of a hierarchy or prioritization scheme for the water supply based on actual supply sources.
Firstly, the allocation of water should respond to available levels in the current water regime, above all in the case of agricultural demand. During wet years, for example, an extra annual volume of $32.4 \mathrm{hm}^{3}$ will be available in comparison to an average year. In second place, the UEV of the water supply provides a means of prioritizing demand nodes that require an increase in efficiency during some stage of the water supply process. Therefore, payment rates could reflect a better estimation that would truly consider the aggregate value of water resources provided by emergy accounting. Although the average UEV is $3.68 \times 10^{13} \mathrm{seJ} / \mathrm{m}^{3}$, for an average year in scenario TWAIU, it is possible to observe nodes with UEV of ranging from $2.25 \times 10^{13}$ to $2.25 \times 10^{14} \mathrm{seJ} / \mathrm{m}^{3}$ (Fig. 12). Given the high demand of the agricultural nodes, these may be the first candidates for examining the possibilities to decrease their UEV. For example, the agricultural node (with identifier 1623 in the annexed databases) that requires the maximum UEV in sub-watershed 42 has nearly a $90 \%$ deficit, and the water supplied to this node comes completely from deep wells, which represents a non-renewable water resource $(E S I=0)$. Therefore, priority should be given to these types of nodes, and its current supply could be complemented with new WWTP links.

This strategy should also consider that for scenario TWAIU, a decrease in the importation of water implies an increase in the extraction of groundwater from a highly exploited aquifer 


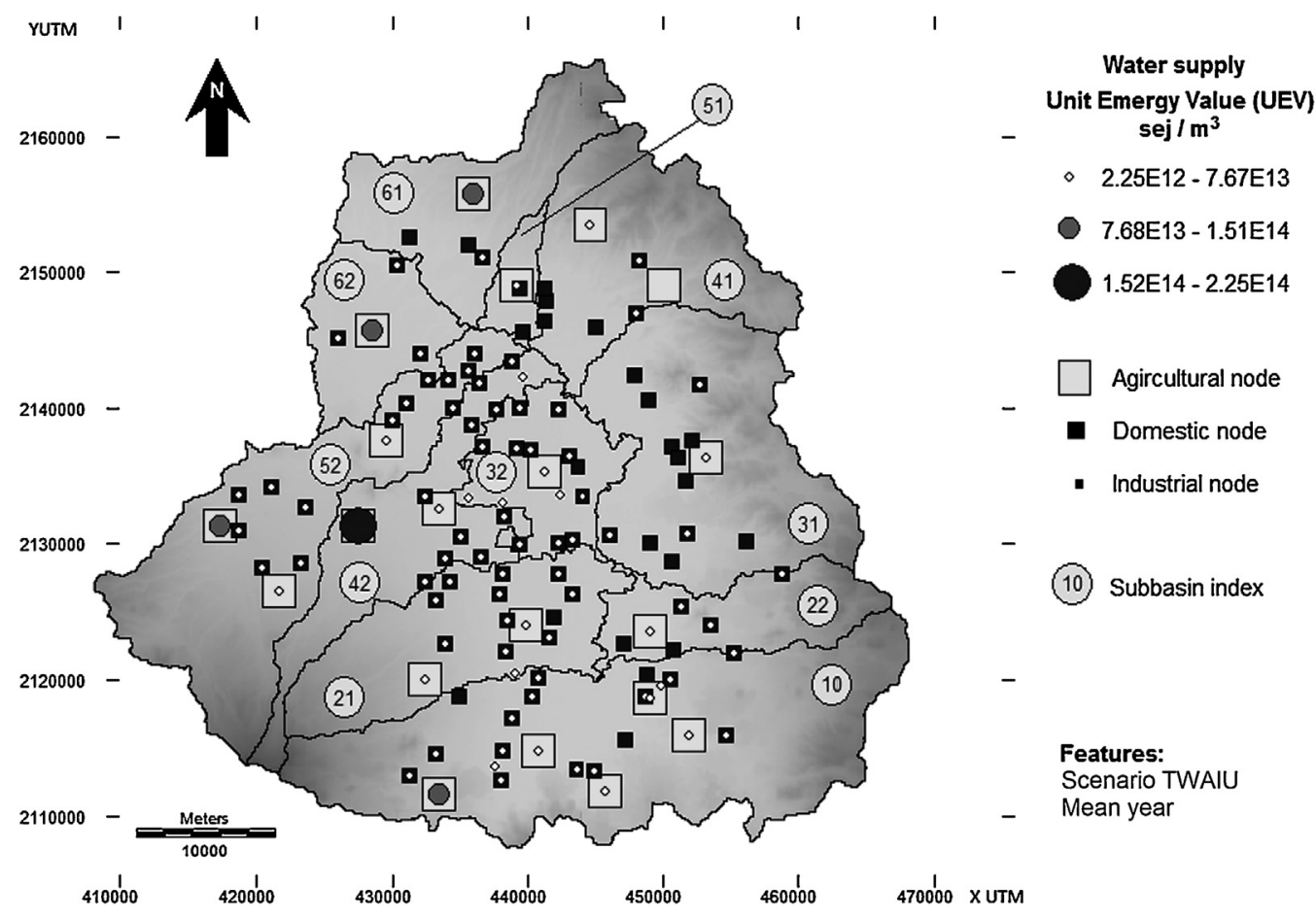

Fig. 12. Unit emergy value of a cubic meter of water supplied under scenario TWAIU with mean yearly precipitation.

(consumption of non-renewable resources). On one hand, this dynamic is feasible in terms of water balance if at the same time, the volume of exported groundwater is reduced. On the other hand, a decrease in the depth of the water table leads to an increase in the energy required to extract it, modifying over time the economic impact associated with the maintenance of deep wells. In other words, taking into consideration the conditions of the allocated volumetric flow for scenario TWAIU (supply of $114.86 \mathrm{hm}^{3} /$ year from groundwater) and the average energy consumption for treating wastewater $\left(11.1 \mathrm{kWh} / \mathrm{m}^{3}\right)$, the substitution of $114.86-97.31=17.55 \mathrm{hm}^{3} /$ year of extractable, non-renewable water resources has an economic impact 1.64 times greater. In agreement with Fonseca et al. (2013a,b), the economic impact of the annual decrease in the Toluca Valley aquifer is USD $0.03 / \mathrm{m}^{3}$ (or in energetic terms: $0.27 \mathrm{kWh} / \mathrm{m}^{3}$ ). In following the proportional tendency, in 37 years the economic impact of supplying the same volume of groundwater will be greater than what it would cost to supply this quantity of water using recycling techniques. Furthermore, if the aggregate value of the emergy of water resources is considered, wherein not only yield but also the conservation of water bodies is promoted, this lapse is reduced to approximately 30 years (Fig. 13).

Generally speaking on the validation of the model results and opposite to several simulation and forecasting models; for instance rainfall- runoff models, where calibration and validation is obligatory to be carried out by means of a measured output variable (in the example: the flow rate); emergy-based models rely mostly on a geobiosphere emergy baseline "GEB". The GEB is derived from solar radiation, tidal momentum and geothermal sources. In other words, it depends on three global sources of energy hard to be measured without inferences. Besides, GEB has acquired numerous values in the past 20 years and therefore it has contributed to the uncertainty of the models (Brown and Ulgiati, 2016). Nevertheless, there could be a reference frame as a kind of verification of both the emergy fluxes and the independent-from-emergy coproducts (in this case the energy consumption and economic impact).
On one hand, the systematic uncertainty of the GEB allows comparing UEV's by multiplying the UEV by the ratio of the new baseline to the previous one (Brown and Ulgiati, 2016). At the case study, the mean UEV of surface water $\left(2.79 \times 10^{12} \mathrm{seJ} / \mathrm{m}^{3}\right)$, seems too greater than those estimated by Buenfil (2001), Brown and Ulgiati (2016) for global streams $\left(7.14 \times 10^{4}\right.$ and $4.5 \times 10^{4} \mathrm{seJ} / \mathrm{m}^{3}$ respectively). However, the surface water in the upper course of Lerma river basin, just as Díaz-Delgado et al. (2014) pointed out, keeps a concentration closer to wastewaters. Because of that, the value of its mean UEV ranges between the values found in literature for irrigation $\left(1.47 \times 10^{12} \mathrm{seJ} / \mathrm{m}^{3}\right.$ by Chen et al., 2011) and wastewater $\left(2.86 \times 10^{12} \mathrm{seJ} / \mathrm{m}^{3}\right.$ by Arias and Brown, 2009). In the case of the groundwater, there is a few studies to compare its UEV, but the groundwater UEV of the Valley of Toluca aquifer remains coherent among the values from $3.25 \times 10^{11}$ to $1.3 \times 10^{12} \mathrm{seJ} / \mathrm{m}^{3}$ estimated by Buenfil (2001).

On the other hand, the UEV's of water supply processes are calculated mostly from the energy consumption in extraction and treatment. Under this context, the informatics tool developed for this study, has estimated the energy consumption as function of both, the power to elevate a water flow rate from a certain deep and the operational features of the wastewater treatment plants. In regards of the scenarios CSC and TWAI, it was required $4.15 \times 10^{14} \mathrm{~J}$ to extract $8.93 \times 10^{7} \mathrm{~m}^{3}$ of water $\left(1.29 \mathrm{kWh} / \mathrm{m}^{3}\right)$, as well as, $1.98 \times 10^{13} \mathrm{~J}$ for the treatment of $1.61 \times 10^{7} \mathrm{~m}^{3}$ of wastewater (USD $\$ 0.038 / \mathrm{m}^{3}$ since USD $\$ 0.11 / \mathrm{kWh}$ by Ávila et al., 2005) respectively.

The mean energy consumption of $2.10 \times 10^{10} \mathrm{~m}^{3}$ groundwater extraction at national level in 2010 (CONAGUA, 2010a) was about $80 \%$ of $1.45 \times 1014 \mathrm{~J}$ of the consumed energy by the agricultural use (SENER, 2012). Furthermore, state government and local authorities invested USD\$6.6 million in the operation of $1.63 \times 10^{6} \mathrm{~m}^{3}$ wastewater treatment at the region (CONAGUA, 2010b). Therefore, and due to the lack of measures, it is possible to accept the estimated energy consumption in comparison with the published mean 


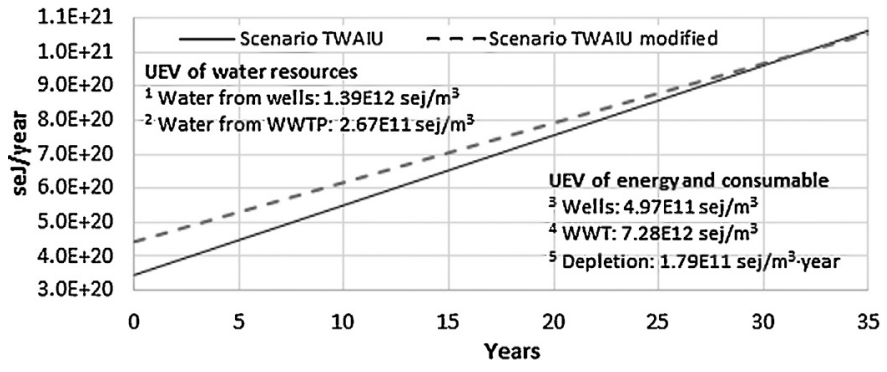

Fig. 13. Projection over time of increased energy usage due to aquifer depletion for scenario TWAIU.

energy consumption for groundwater extraction $\left(1.54 \mathrm{kWh} / \mathrm{m}^{3}\right)$ and wastewater treatment (USD\$ 0.04/ $\mathrm{m}^{3}$ ).

\section{Conclusions}

The methodology presented in the current work has allowed for the development of criteria and parameters to guide the supply and allocation of water resources by means of geoinformatics tools. These tools are oriented towards the integrated and sustainable management of regions delimited by hydrological watersheds and follow an emergy approach.

Three hydrogeomatic modules were developed for operating in a geographic information system (GIS) environment using the Idrisi package. Two of these tools were focused on facilitating the emergy accounting for two of the water supply processes with the greatest impact: extraction of groundwater and treatment of wastewater. The third module is oriented towards evaluating the allocation of water resources by means of three indicators: the water deficit, the environmental sustainability index (ESI), and the economic impact produced.

In contrast to conventional emergy accounting, the modules developed for the water supply processes estimated the emergy of the involved elements (water, infrastructure, energy, consumables, etc.) as a function of the water volume allocated between the offer and demand nodes. In this way, it was possible to estimate the unit emergy values (UEV) for different conditions and volumetric flows of water. For groundwater, the emergy associated with its extraction resulted in a non-linear function due to losses in the hydraulic head that may be introduced at some point in the supply process. In the case of wastewater treatment, it was necessary to separate the involved components found in the literature in order to define the UEV as a function of the type, capacity, and operational processes of a wastewater treatment plant.

The spatial distribution of information by means of a GIS allowed for demand nodes with critical deficits to be located, according to the criteria of the evaluation module. This included the identification of strategic zones where changes in infrastructure may be recommended. In this context, although the ESI estimated the relationship between emergy yield stemming from the socioeconomic sub-system and the generated environmental load, it does not represent the satisfaction of the demand for water resources (due to the fact that this factor communicates emergy flows emitted rather than required). For this, the information provided by the ESI is complemented by the determination of the water deficit, which indicates the proportion of the demand that is satisfied. In addition, the evaluation of emergy may be associated with the payment of environmental services that reflects the true cost of delivering a service (Brown et al., 2010), although in developing countries like Mexico, there are still several barriers to surpass, including those addressed in this manuscript. The economic impact, the proposed indicator that determines the equivalent cost of the energy utilized in supply processes, may be used as an indicator to transition from the current management system (that solely translates benefits and costs in monetary terms) towards a management system based on concepts of ecological economics.

The developed modules generate databases that included, on a monthly basis, the fundamental fields for an emergy table (input, flow, emergy, type of emergy flow) and additionally, fields for the coefficients that estimate the emergy and energy as a function of the allocated water volume, the identifiers for supply and demand nodes (for locating these geographically), and finally, the description of the supply source.

This one is a deterministic model which relies strongly on the input data quality. It supposed to be limited on databases that have approved quality tests. However, this informatics tool will allow developing sensitivity analysis of the variables which the emergy flow depends on, for instance the groundwater extraction depth, pipelines diameter and capacity of wastewater treatment plant among others. This way, the model could provide for later versions of the informatics tool a set of ranges in function of the more sensible variables.

In the study area of the Upper Course of the Lerma River (UCLR), four scenarios with distinct infrastructure for supplying water resources were evaluated. In general, the overall fragility of the system is evident across all of the evaluated scenarios, since the use of renewable resources represents less than half of the total demand for water resources. The scenario that provided the best ESI with the least economic impact involved the recycling of water for all uses, including domestic use with limitations, resulting in water below drinking level quality (scenario TWAIU). However, up to $40 \%$ of the current capacity of WWTP is directed towards demand nodes that do not require drinking water quality (above all, agricultural nodes). Although the treatment of water to drinking level quality by treatment plants enables its provision to a greater number of nodes (in responding to an ever increasing demand), currently and in terms of the environmental sustainability index and economic impact, other objectives must also be addressed, including: a) linking current WWTP to more agricultural nodes in order to use $100 \%$ of their capacity; b) implementing infrastructure for recycling water, destined for toilet and garden uses in urban demand nodes; and c) constructing WWTP in strategic zones of the sub-watersheds with the greatest water deficits.

In addition to the proposed water management strategies, a time frame was also established for when the emergy associated with extraction of groundwater would surpass that associated with the implementation of water-recycling infrastructure, a phenomenon resulting from decreasing groundwater levels over time. However, a complementary study is recommended that would take into consideration the following: a) the opportunity cost of treating certain volumes of water that are not exploited by any use and b) the increase in water demand over time due to demographic growth. An additional study could examine the difference between the true economic impact of the energy utilized for supplying water and the actual rate that is paid by users. For such a study, it would be possible to determine where the greatest monetary deficit exists and the geographical location of users whose consumption is likely supported by subsidies, even if inadvertently.

Finally, emergy accounting as a function of the supplied volume of water was utilized for the construction of an optimization model, with the goal of minimizing the emergy flow required for satisfying water demand. Furthermore, it is possible for an emergy accounting to be focused on the services and products generated at demand nodes, where an optimization model could replace the cost-benefit analyses that are currently used to assess the management of water resources. 


\section{Acknowledgement}

The authors gratefully aknowledge the support received from Consejo Nacional de Ciencia y Tecnologia (CONACyT) through project no. 248327.

\section{Appendices A-B. Attached databases and software section}

Attached file provides 12 databases corresponding with three hydrological regimes per each one of the four scenarios of infrastructure. Each database is comprised of 13 sheets: 12 corresponding a monthly emergy table and one (called "EmergyAccount") with the annual summary.

The "EmergyAccount" sheet provides: a) monthly water supply $\left(\mathrm{m}^{3}\right)$ and UEV $\left(\mathrm{seJ} / \mathrm{m}^{3}\right)$, total supply $\left(\mathrm{m}^{3} /\right.$ year), emergy (seJ/year) and annual average UEV (seJ/m $\mathrm{m}^{3}$ ) per demand node; b) total (row called "-1"), mean (row called "-2") and standard deviation (row called "-3") of supply $\left(\mathrm{m}^{3} / \mathrm{month}\right)$ and UEV $\left(\mathrm{seJ} / \mathrm{m}^{3}\right)$ considering all of the demand nodes.

Supplementary data associated with this article can be found, in the online version, at http://dx.doi.org/10.1016/j.ecoleng.2016.11. 034.

\section{References}

Almeida, C.M.V.B., Barrella, F.A., Giannetti, B.F., 2007. Emergetic ternary diagrams: five examples for application in environmental accounting for decision-making. J. Clean Prod. 15, 63-74.

Ávila, S., Muñoz, C., Jaramillo, L., Martínez, A., 2005. Un análisis del subsidio a la tarifa 09. Gaceta Ecológica 75, 65-76.

Arbault, D., Rugani, B., Tiruta-Barna, L., Benneto, E., 2014. A first global and spatially explicit emergy database of rivers and streams based on high-resolution GIS-maps. Ecol. Modell. 281, 52-64.

Arias, M.E., Brown, M.T., 2009. Feasibility of using constructed treatment wetlands for municipal wastewater treatment in the Bogotá Savannah, Colombia. Ecol. Eng. 35, 1070-1078.

BANCO DE MÉXICO, 2015. Serie Histórica Diaria Del Tipo De Cambio Peso-dólar (Available online at: www.banxico.org.mx [Accesed 2.10.2015.]).

Balairón, L., 2000. Gestión De Recursos hídricos. Edicions de la Universitat Politécnica de Catalunya, SL, Barcelona (488 pp).

Borland Software Corporation, 2002. Delphi 7 for Windows, Developers Guide. Borland Software Corporation, USA (1100 p.).

Brown, M.T., Bardi, E., 2001. Emergy of Ecosystems, Folio \#3. HandBook of Emergy Evaluation. Center of Environmental Policy, University of Florida, Gainesville (94 pp.).

Brown, M.T., Ulgiati, S., 1997. Emergy-based indices and ratios to evaluate sustainability: monitoring economies and technology toward environmentally sound innovation. Ecol. Eng. 9, 51-69.

Brown, M.T., Ulgiati, S., 2016. Emergy assessment of global renewable sources. Ecol. Model. http://dx.org/ 10.1016/j.ecolmodel.2016.03.010.

Brown, M.T., Martínez, A., Uche, J., 2010. Emergy analysis applied to the estimation of recovery of costs for water services under the European Water Framework Directive. Ecol. Modell. 221, 2123-2132.

Buenfil, A.A., 2001. Emergy Evaluation of Water, Ph.D Paper. Department of Environmental Engineering Sciences, University of Florida (2001).

CONAGUA, 2010a. Estadísticas Del Agua En México, Edición 2010. SEMARNAT, México (249 p. [in Spanish]).

CONAGUA, 2010b. Situación Del Subsector Agua Potable, Alcantarillado Y Saneamiento, Edición 2010. SEMARNAT, México (165 p. [in Spanish]).

Chen, D., Webber, M., Chen, J., Luo, Z., 2011. Emergy evaluation perspectives of an irrigation improvement project proposal in China. Ecol. Econ. 70, 2154-2162.

Chung, G., Lansey, K., Blowers, P., Brooks, P., Ela, W., Stewart, S., Wilson, P., 2008. A general water supply planning model: evaluation of decentralized treatment. Environ. Modell. Softw. 23, 893-905.

Chung, G., Lansey, K., Bayraksan, G., 2009. Reliable water supply system design under uncertainty. Environ. Modell. Softw. 24, 449-462.

Díaz-Delgado, C., Fonseca, C.R., Esteller, M.V., Guera-Cobián, V.H., Fall, C., 2014. The establishment of integrated water resources management based on emergy accounting. Ecol. Eng. 63, 72-87.

DOF, 2009. Acuerdo Por El Que Se Dan a Conocer Los límites De 188 Acuíferos De Los Estados Unidos Mexicanos, Los Resultados De Los Estudios Realizados Para Determinar Su Disponibilidad Media Anual De Agua Y Sus Planos De Localización. Secretería de Medio Ambiente y Recursos Naturales, México.

Eastman, J.R., 2006. Idrisi Andes Guide to GIS and Image Processing. Clark University, Worceter, MA USA, 327 pp.
Eker, I., Kara, T., 2003. Operation and control of water supply system. ISATransactions 42, 461-473.

Esteller, M.V., Díaz-Delgado, C., 2002. Environmental effects of aquifer overexploitation: a case of study in the Highlands of Mexico. Environ. Manage. 29 (2), 266-278

Esteller, M.V., Rodríguez, R., Cardona, A., Padilla-Sánchez, L., 2011. Evaluation of hydrochemical changes due to intensive aquifer exploitation: case studies from Mexico. Environ. Monit. Assess., http://dx.doi.org/10.1007/s10661-0112376-0.

Fonseca, C.R., Díaz-Delgado, C., Hernández, M., Esteller, M.V., 2013a. Urban water demand in Mexico: spatial modelling base on geographic information system. Interciencia 38 (1), 17-25

Fonseca, C.R., Esteller, M.V., Díaz-Delgado, C., 2013b. Territorial approach to increased energy consumption of water extraction from depletion of a highlands Mexican aquifer. J. Environ. Manage. 128, 920-930.

Fonseca, C.R., 2014. Sistema De Modelos Termohidrológicos Para La Evaluación De Eficiencia Y Asignación De Recursos hídricos. PhD Thesis. CIRA-UAEMex, México (270 p.)

IMTA, 2009. Censo De Explotación Del Acuífero Valle De Toluca, Internal Report. México.

Lazzaretto, A., 2009. A critical comparison between thermoeconomic and emergy analyses algebra. Energy 34, 2196-2205.

Lv, C., Wu, Z., 2009. Emergy analysis of regional water ecologic- economic system. Ecol. Eng. 35, 703-710.

Macdonald, A.M., Dochartaigh, Ó., Calow, B.É., Shalabi, R.C., Selah, Y.K., Merrett, S., 2009. Mapping groundwater development costs for the transboundary Western Aquifer Basin, Palestine/Israel. Hydrol. J. 17, 1579-1587.

Marvuglia, A., Benetto, E., Rios, G., Rugani, B., 2013. SCALE: Software for calculating emergy based on life cycle inventories. Ecol. Modell. 248, 80-91.

Mellino, S., Buonocore, E., Ulgiati, S., 2015. The worth of land use: a GIS-emergy evaluation of natural and human-made capital. Sci. Total Environ. 506, 137-148.

Mo, W., Zhang, Q., Mihelcic, J.R., Hokanson, D.R., 2011. Embodied energy comparison of surface water and groundwater supply options. Water Res. 45 5577-5586.

Odum, H.T., 1996. Environmental Accounting. Emergy and Environmental Decision Making. John Wiley \& Sons, Inc., Gainesville, Florida, 370 pp.

Palacios, O.L., Palacios, E., Peña, S., Gutiérrez, N., 2002. Escenarios para el aprovechamiento sustentable del acuífero del Valle de Querétaro. Agrociencia $36(1), 1-10$

Paredes, J., 2010. Determinación Del índice De Vulnerabilidad De Contaminación Del Acuífero Valle De Toluca Mediante La Adecuación Del método SINTACS, Master Thesis. CIRA-UAEMex, México.

Pulselli, F.M., Coscieme, L., Bastianoni, S., 2011a. Ecosystem services as a counterpart of emergy flow to ecosystems. Ecol. Modell. 222, 2924-2928.

Pulselli, F.M., Patrizi, N., Focardi, S., 2011b. Calculation of the unit emergy value of water in an italian watershed. Ecol. Modell. 222, 2929-2938.

Roche, P.A., Valiron, F., Coulomb, Villesot, D., 2001. Infrastructure integration issues. In: Maksimovic, C., Tejada-Guibert, J.A. (Eds.), Frontiers in Urban Water Management, Deadlock of Hope. IWA Publishing, UK, 416 pp.

Rozos, E., Makropoulos, C., 2013. Source to tap urban water cycle modelling. Environ. Modell.Softw. 41, 139-150.

SEMARNAT, 2010a. Plan Maestro Para La Restauración Ambiental De La Cuenca Alta Del río Lerma. Diagnóstico Ecosistémico Tomo III. Marco Físico-Biótico, Gobierno del Estado de México/Universidad de Chapingo, 229 pp.

SEMARNAT, 2010b. Plan Maestro Para La Restauración Ambiental De La Cuenca Alta Del río Lerma. Diagnóstico Ecosistémico Tomo V. Infraestructura De La CARL. Gobierno del Estado de México/Universidad de Chapingo, 170 pp.

SEMARNAT, 2011. Reglas De Operación Para Los Programas De Infraestructura Hidroagrícola Y De Agua Potable. Alcantarillado y Saneamiento a cargo de la Comisión Nacional del Agua, Diario Oficial de la Federación, México, 60 pp.

SENER, 2012. Balance Nacional De Energía 2011. Subsecretaría de planeación energética y desarrollo tecnológico, México, 159 p.[in Spansih].

Secretaría De Energía, 1997. Norma Oficial Mexicana NOM-010-ENER-1996, Eficiencia Energética De Bombas Sumergibles. Límites y método de prueba, Diario Oficial de la Federación, México.

Sotelo, G., 2002. Hidráulica General Volumen I Fundamentos. Limusa (562 pp.)

WWAP, 2006. Water a Shared Responsability, 2nd UN World Water Development Report. UNESCO (600 pp.)

Van Camp, M., Radfar, M., Walraevens, K., 2010. Assessment of groundwater storage depletion by overexploitation using simple indicators in an irrigated closed aquifer basin in Iran. Agric. Water Manage. 97, 1876-1886.

Vassallo, P., Paoli, C., Fabiano, M., 2009. Emergy required for the complete treatment of municipal wastewater. Ecol. Eng. 35, 687-694.

Vassallo, P., Paoli, C., Rovere, A., Montefalcone, M., Morri, C., Bianchi, C.N., 2013. The value the seagrass Posidonia oceanica: a natural capital assesment. Marine Pollut. Bull. http://dx.org/10.1016/j.marpolbul.2013.07.044.

Zhou, J.B., Jiang, M.M., Chen, B., Chen, G.Q., 2009. Emergy evaluations for constructed wetlands and conventional wastewater treatments. Commun. Nonlin. Sci. Numer. Simulat. 14, 1781-1789. 